\title{
Uncertainty characterization of AOD for the AATSR dual and single view retrieval algorithms
}

P. Kolmonen ${ }^{1}$, A.-M. Sundström ${ }^{2}$, L. Sogacheva ${ }^{1}$, E. Rodriguez ${ }^{1}$, T. Virtanen ${ }^{2}$, and $G$. de Leeuw ${ }^{1,2}$

${ }^{1}$ Finnish Meteorological Institute, Erik Palmenin Aukio 1, 00560 Helsinki, Finland

${ }^{2}$ Department of Physics, University of Helsinki, Gustav Hällströmin katu 2a, 00560 Helsinki, Finland

Received: 6 March 2013 - Accepted: 18 April 2013 - Published: 29 April 2013

Correspondence to: P. Kolmonen (pekka.kolmonen@ @mi.fi)

Published by Copernicus Publications on behalf of the European Geosciences Union.

AATSR aerosol retrieval uncertainty

P. Kolmonen et al.

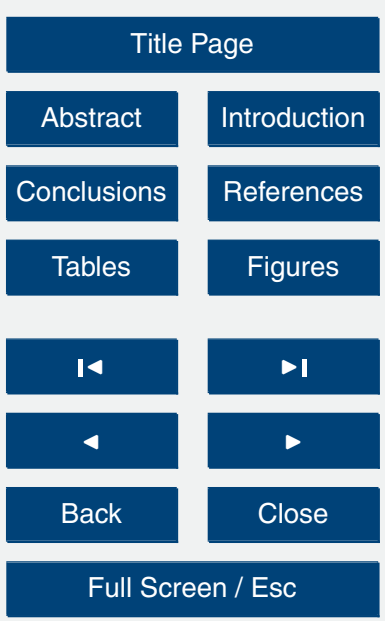

Printer-friendly Version

Interactive Discussion 


\section{Abstract}

The uncertainty associated with satellite-retrieved aerosol properties is needed when these data are used to constrain chemical transport or climate models by using data assimilation. Global uncertainty as provided by comparison with independent ground5 based observations is usually not adequate for that purpose. Rather the per-pixel uncertainty is needed. In this work we describe how these are determined in the AATSR dual and single view aerosol retrieval algorithms (ADV and ASV) which are used to retrieve aerosol optical properties from reflectance measured at the top of the atmosphere. AATSR is the Aerosol Along-Track Scanning Radiometer which flies on the 10 European Space Agency Environmental Satellite ENVISAT. In addition, issues related to multi-year retrievals are described and discussed. The aerosol optical depth (AOD) retrieved for the year 2008 is validated versus ground-based AERONET sun photometer measurements with good agreement $(r=0.85)$. The comparison of the AOD uncertainties with those provided by AERONET shows that they behave well in a sta15 tistical sense. Other considerations regarding global multi-year aerosol retrievals are presented and discussed.

\section{Introduction}

Atmospheric aerosols have a strong effect on the Earth climate due to their reflection and absorption of solar radiation (direct effect) and because they can act as cloud condensation nuclei and thus affect cloud properties (indirect effect). Aerosol particles also have an adverse effect on human health and are important for heterogeneous chemical processes in the atmosphere. To assess the effects of aerosols, their spatial and temporal distributions need to be known. Accurate information can be obtained from ground-based measurements, but these are representative for only a limited area. Information on regional and global scales can be obtained from satellite data. Algorithms have been developed to retrieve information from the radiation at the top of
AMTD

$6,4039-4075,2013$

AATSR aerosol retrieval uncertainty

P. Kolmonen et al.

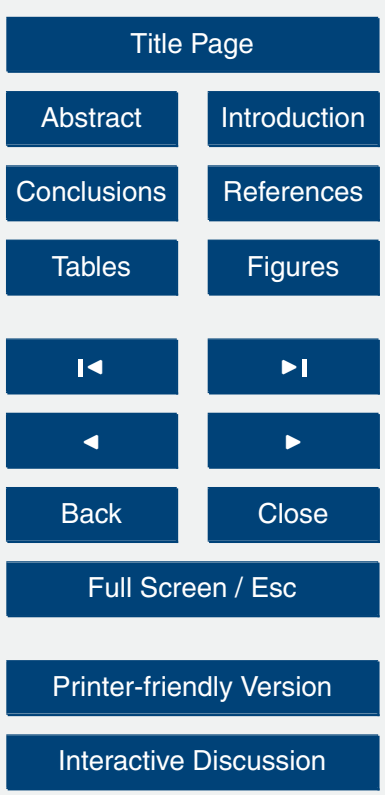


the atmosphere (TOA) measured by satellite-based instruments, i.e. radiometers and spectrometers. This information can be used to constrain chemical transport models by data assimilation (e.g. Benedetti et al., 2009) or to evaluate model results. Such combination of measurements and models aims to provide the best possible information on 5 the occurrence and concentrations of aerosol particles.

For the assimilation of satellite-retrieved aerosol properties in transport models the data must meet a number of requirements which have been studied extensively by, e.g., Hyer et al. (2011). One of these is a thorough understanding of the uncertainty characteristics. Global uncertainties as provided by comparison with independent ground10 based observations are usually not adequate for that purpose. Rather the per-pixel uncertainty is needed. This is mainly because of the large variation of the reflectance of the underlying surface. For instance, the TOA reflectance over a highly reflecting surface is more intense than over a dark surface but the aerosol signal over adjacent pixels would be the same and, thus, more difficult to entangle form the total TOA signal. 15 Hence, the retrieval uncertainty depends on the underlying surface. Another critical issue for data assimilation is the possible bias in the data. Data outliers can lead the assimilation to erroneous results.

In global climate modelling the assimilation of the retrieved aerosol properties differs slightly. Huneeus et al. (2012) show that a uniform uncertainty in the satellite-retrieved data needs to be used to avoid unwanted bias in the model results. Satellite retrievals can be used, however, as reference for global models, and well-defined retrieval uncertainty is very much needed for this purpose.

In this paper the retrieval of aerosol properties using TOA radiances measured by the Advanced Along-Track Scanning Radiometer (AATSR), flying on the European Space

25 Agency (ESA) environmental satellite ENVISAT, is described, including uncertainty characterisation. AATSR is the third in a series of along track scanning radiometers. They were originally designed to measure Sea Surface Temperature (SST) with high accuracy and precision. The instrument offers two views, one near-nadir and the other one at $55^{\circ}$ forward, which together with the multiple wavelengths renders the instrument
AMTD

$6,4039-4075,2013$

\section{AATSR aerosol retrieval uncertainty \\ P. Kolmonen et al.}

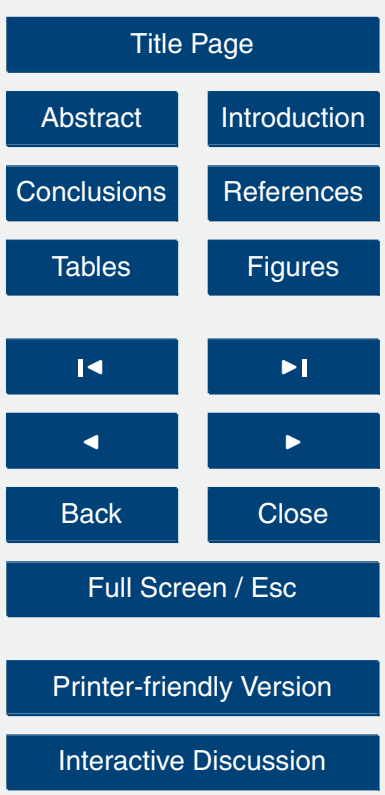


suitable for the retrieval of aerosol properties. The centre wavelengths of the AATSR channels are $0.555,0.659,0.865,1.61,3.70,10.85$, and $12.00 \mu \mathrm{m}$.

A number of algorithms have been developed for aerosol retrieval over land using AATSR data. The retrieval algorithms described in this paper for use over land 5 and water build on those developed by Veefkind et al. (1998) and Veefkind and de Leeuw (1998), respectively. The dual-view algorithm (ADV) for aerosol retrieval over land was originally developed by Veefkind et al. (1999). It differs significantly from the Swansea algorithm by North et al. (1999); Grey et al. (2006), or the Oxford-RAL algorithm (Thomas et al., 2009) in the way the surface reflectance is handled. ADV uses 10 both views to eliminate the surface reflectance from the TOA signals as described below. In the Swansea algorithm, a surface reflectance model is used which makes it possible to retrieve aerosol properties and surface reflectance simultaneously (North et al., 1999). The Oxford-RAL algorithm relies on information from the retrieval of another instrument: the land surface bi-directional reflectance product of MODIS (MODerate resolution Imaging Spectrometer).

The over-ocean retrieval is based on modelling of the TOA reflectance and then minimizing the discrepancy between the measured and modelled reflectance. The ASV (AATSR Single-View) algorithm, described below, currently utilizes only one of the AATSR views.

In this paper we describe recent improvements and extensions of the ADV and ASV algorithms. The principles of the ASV and ADV methods have been introduced in several earlier publications (Veefkind and de Leeuw, 1998; Veefkind et al., 1999; Curier at al., 2009),but this information in necessarily duplicated to some extent in Sects. 2 and 3, to provide context for recent modifications and improvements of the algorithms and extensions, e.g., to include uncertainty estimation (Sects. 2.3 and 3.4) and to remove outliers (Sect. 4.2). With AATSR and it's predecessor instrument ATSR-2, a $17 \mathrm{yr}$ aerosol data set can be retrieved. Issues related to producing the time series are introduced and discussed in Sect. 4.3. AOD data for one year and their uncertainties are evaluated by comparison with AERONET data in Sect. 5 .
AMTD

6, 4039-4075, 2013

\section{AATSR aerosol retrieval uncertainty \\ P. Kolmonen et al.}

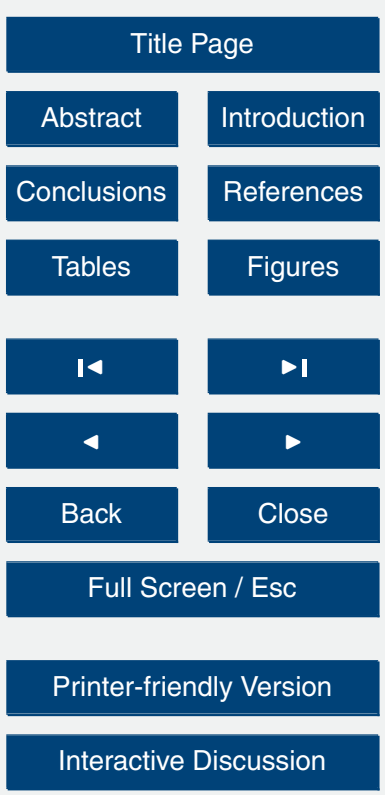




\section{ADV algorithm for over land retrieval}

\subsection{Formal background of the dual-view algorithm}

The AATSR dual-view algorithm ADV uses the TOA reflectance at 3 wavelengths in both the nadir and forward views for retrieval of aerosol properties over land (Veefkind 5 et al., 1999, 2000; Robles González, 2003; Curier at al., 2009). These properties include aerosol optical depth (AOD) for three wavelengths (nominally $0.555,0.659$ and $1.61 \mu \mathrm{m})$. In addition, an aerosol model is retrieved.

The aerosol model is a mixture of four aerosol components each of which is described by a log-normal size distribution defined by an effective radius and a standard deviation (see Sect. 2.2), and a complex refractive index. Two of the aerosol components define small particles and the other two coarse particles. One of the small particle components is non-absorbing while the other one is strongly absorbing. By mixing these two components the absorption of the small particles can arbitrarily be set. The coarse particle components are sea salt and desert dust. Desert dust is composed of non-spherical particles; the other three components are assumed to consist of spherical particles. The aerosol components are adopted from the ESA Aerosol CCI (Climate Change Initative) project ${ }^{1}$ (Holzer-Popp et al., 2013; de Leeuw et al., 2013). The properties of the components are described in Table 1. The aerosol model used in the retrieval is determined by first mixing the small and large components separately, and then mixing the ensuing small and coarse modes. The mixing ratios are selected during the retrieval process by fitting the aerosol model to the reflectance measured at three (four over ocean) wavelengths, except for the dust fraction which is selected from an aerosol climatology based on the median of 13 global models as described in (Holzer-Popp et al., 2013). The mixing ratio of non-absorbing and absorbing fine components is retrieved semi-freely. The mixing ratio can have any value in the range

${ }^{1}$ http://www.esa-aerosol-cci.org/

AMTD

$6,4039-4075,2013$

\section{AATSR aerosol retrieval uncertainty \\ P. Kolmonen et al.}

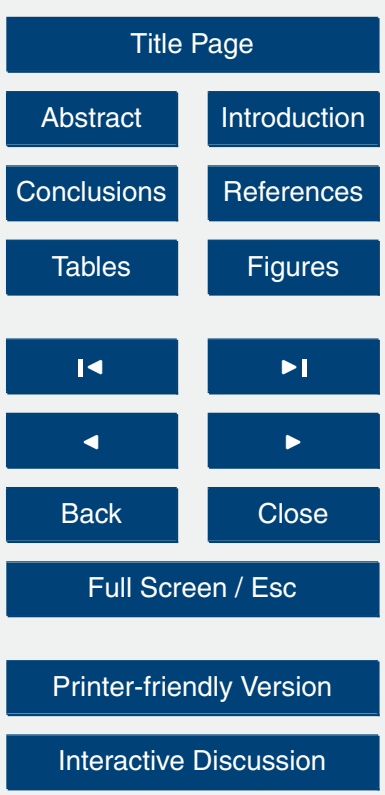


of \pm 0.3 from the AEROCOM climatology value. The fine - coarse mixture is retrieved completely independent of the climatology.

The algorithm is based on a number of assumptions:

- TOA reflectance $\rho$ is of the form (Veefkind et al., 2000)

$$
\rho\left(\mu_{0}, \mu, \phi, \lambda\right)=\rho_{\mathrm{a}}\left(\mu_{0}, \mu, \phi, \lambda\right)+\frac{T\left(\mu_{0}, \mu, \phi, \lambda\right) \rho_{\mathrm{g}}\left(\mu_{0}, \mu, \phi, \lambda\right)}{1-s(\lambda) R_{\mathrm{s}}(\lambda)},
$$

where $\rho_{\mathrm{a}}$ is the reflectance due to the atmosphere, $\rho_{\mathrm{g}}$ is the surface reflectance, $T$ is the product of downward and upward atmospheric transmittance, $s$ is the atmospheric backscatter ratio, and $R_{\mathrm{s}}$ is the surface albedo. Reflectance and transmittance parameters: $\mu_{0}$ is the solar zenith angle, $\mu$ is the viewing (satellite) zenith angle, $\phi$ is the relative azimuth angle between the sun and the satellite, and $\lambda$ is the wavelength. Note that, for method development purposes, multiple scattering between the surface and the atmosphere is assumed to be angle-independent i.e. surface albedo $R_{\mathrm{s}}$ is used in the numerator of Eq. (1) instead of surface reflectance $\rho_{\mathrm{g}}$. It has been suggested that multiple scattering in the surface-atmosphere system will lead to isotropically distributed scattering (Wanner et al., 1997) which supports the use of surface albedo instead of reflectance.

- Atmospheric reflectance

$\rho_{\mathrm{a}}\left(\mu_{0}, \mu, \phi, \lambda\right)=\rho_{\mathrm{R}}\left(\mu_{0}, \mu, \phi, \lambda\right)+\rho_{\text {aer }}\left(\mu_{0}, \mu, \phi, \lambda\right)$,

where $\rho_{\mathrm{R}}$ is reflectance due to Rayleigh scattering and $\rho_{\mathrm{aer}}$ is reflectance due to aerosols.

- Reflectance due to aerosols is computed using the modified linear mixing method by Abdou et al. (1997) assuming external mixture of the aerosol particles. The method as adapted to ADV for two aerosol components is

$$
\rho_{\text {aer }}=b_{1} \frac{\omega_{\text {mix }}}{\omega_{1}} e^{-\tau_{1}\left|\omega_{1}-\omega_{\text {mix }}\right|} \rho_{1}+b_{2} \frac{\omega_{\text {mix }}}{\omega_{2}} e^{-\tau_{2}\left|\omega_{2}-\omega_{\text {mix }}\right|} \rho_{2},
$$

\section{AATSR aerosol retrieval uncertainty \\ P. Kolmonen et al.}

\section{Title Page}

Abstract Introduction

\section{Full Screen / Esc}

Printer-friendly Version

Interactive Discussion 
where $\omega$ is the single scattering albedo (SSA) and $\tau$ is AOD. Subscripts 1 and 2 refer to two aerosol components while mix refers to their mixing ratio. Reflectance due to an aerosol component is $\rho$, and SSA mixture is

\section{AMTD}

$\omega_{\text {mix }}=b_{1} \omega_{1}+b_{2} \omega_{2}$.

For the weighting coefficients $b_{1}+b_{2}=1$. The modified linear mixing method is applied to better account for the effects of mixing two aerosol components with different absorbing properties. This is done by introducing the single scattering albedo into linear mixing. If the SSAs of the aerosol components are identical, Eq. (3) simplifies to

$\rho_{\mathrm{aer}}=b_{1} \rho_{1}+b_{2} \rho_{2}$.

The needed aerosol transmittance is computed using linear mixing.

- The ratio of the surface reflectance measured in the forward and nadir views, $k$, is independent of wavelength (Flowerdew and Haigh, 1995):

$k=\frac{\rho_{\mathrm{g}}^{\mathrm{f}}\left(\mu_{0}, \mu, \phi, \lambda\right)}{\rho_{\mathrm{g}}^{\mathrm{n}}\left(\mu_{0}, \mu, \phi, \lambda\right)}$,

where $\rho_{\mathrm{g}}^{\mathrm{f}}$ and $\rho_{\mathrm{g}}^{\mathrm{n}}$ are the forward and nadir surface reflectance, respectively. The $k$ ratio is evaluated for the measured reflectance in the $1.61 \mu \mathrm{m}$ wavelength band using equation

$k=\frac{\rho^{\mathrm{f}}\left(\mu_{0}, \mu, \phi, 1.61 \mu \mathrm{m}\right)}{\rho^{\mathrm{n}}\left(\mu_{0}, \mu, \phi, 1.61 \mu \mathrm{m}\right)}$.

The aerosol contribution at this wavelength is relatively small (except in the presence of coarse particles such as dust or sea spray aerosol).

AATSR aerosol retrieval uncertainty

P. Kolmonen et al.

Title Page

Abstract

Introduction

Conclusions

References

Tables

Figures

14

$\Delta$

4

4

Back

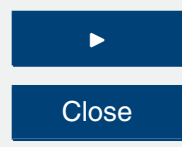

Full Screen / Esc

Printer-friendly Version

Interactive Discussion

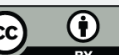


- The $k$ ratio is not reliable for bright surface reflectance. For this reason, if the measured nadir reflectance at $1.61 \mu \mathrm{m}$ is above 0.45 , retrieval is not done.

- The $0.865 \mu \mathrm{m}$ channel is excluded from the retrieval because the $k$ ratio assumption is usually not valid as there is a strong reflectance by vegetation at this wavelength (Robles González et al., 2000).

With these assumptions Eq. (1) can be written separately for the forward and nadir views. Then, by combining these equations while keeping in mind that the multiple scattering is assumed to be angle independent, relation

$\frac{\rho^{\mathrm{n}}\left(\mu_{0}, \mu, \phi, \lambda\right)-\rho_{\mathrm{a}}^{\mathrm{n}}\left(\mu_{0}, \mu, \phi, \lambda\right)}{\rho_{\mathrm{g}}^{\mathrm{n}}\left(\mu_{0}, \mu, \phi, \lambda\right) T^{\mathrm{n}}\left(\mu_{0}, \mu, \phi, \lambda\right)}=\frac{\rho^{\mathrm{f}}\left(\mu_{0}, \mu, \phi, \lambda\right)-\rho_{\mathrm{a}}^{\mathrm{f}}\left(\mu_{0}, \mu, \phi, \lambda\right)}{\rho_{\mathrm{g}}^{\mathrm{f}}\left(\mu_{0}, \mu, \phi, \lambda\right) T^{\mathrm{f}}\left(\mu_{0}, \mu, \phi, \lambda\right)}$

10 can be made formally. The key aspect of the dual-view algorithm is to introduce the $k$ ratio in Eq. (8) to obtain

$\frac{\rho^{\mathrm{n}}\left(\mu_{0}, \mu, \phi, \lambda\right)-\rho_{\mathrm{a}}^{\mathrm{n}}\left(\mu_{0}, \mu, \phi, \lambda\right)}{T^{\mathrm{n}}\left(\mu_{0}, \mu, \phi, \lambda\right)}=\frac{\rho^{\mathrm{f}}\left(\mu_{0}, \mu, \phi, \lambda\right)-\rho_{\mathrm{a}}^{\mathrm{f}}\left(\mu_{0}, \mu, \phi, \lambda\right)}{k T^{\mathrm{f}}\left(\mu_{0}, \mu, \phi, \lambda\right)}$.

Now all the needed knowledge about surface reflectance is in the $k$ ratio.

\subsection{Computational aspects of ADV}

15 Modeled values of the atmospheric reflectance $\rho_{\mathrm{a}}$ and transmittance $T$ must be determined in order to use Eq. (9) for the retrieval of aerosol properties. These values, together with other information, can be computed using radiative transfer (RT) methods. RT methods provide a way to solve the forward problem of the retrieval which for the case of atmospheric reflectance can be stated as: for given atmospheric conditions (aerosol and gas concentrations) determine the amount of incoming solar radiation that is reflected from the atmosphere towards a satellite instrument. Note that the surface reflectance contribution is omitted here as the ADV algorithm formally eliminates it.

AATSR aerosol retrieval uncertainty

P. Kolmonen et al.

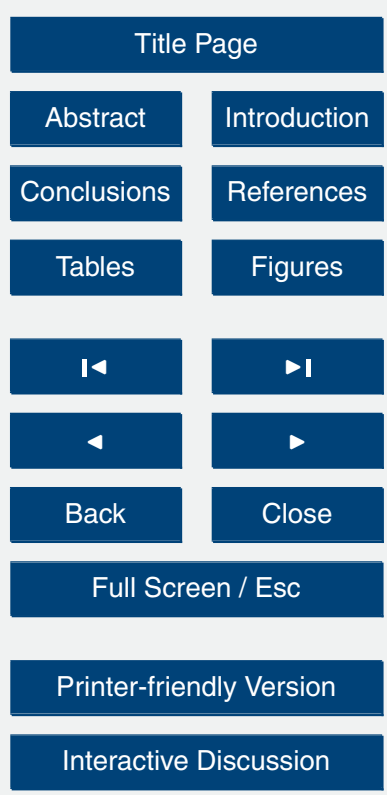


During a retrieval the forward problem must be solved numerous times which is time consuming. The most common technique to overcome this is to perform the radiative transfer calculations for a set of fixed variables before the retrieval. The calculated values are arranged into a multi-dimensional array that is called a look-up-table (LUT). 5 During the retrieval the actual values for the required variables can be quickly obtained by interpolation between values available from the LUT. The chosen RT algorithm that is used with ADV is DAK (Doubling Adding KNMI), Haan et al. (1987). To ensure reliable LUT values, the RT algorithm is limited to solar zenith angles smaller than $75^{\circ}$.

LUTs are computed for each aerosol component. The size distribution of an aerosol 10 component is described by a log-normal number size distributions of the form

$$
\frac{\mathrm{d} N}{\mathrm{~d} \ln r}=\frac{N_{0}}{\ln \sigma \sqrt{2 \pi}} \exp \left(-\frac{\ln ^{2}\left(r / r_{\mathrm{g}}\right)}{2 \ln ^{2} \sigma}\right)
$$

where $r$ is the particle radius, $r_{\mathrm{g}}$ is the geometric mean radius, $\sigma$ is the standard deviation $\sigma$ (Heintzenberg, 1994). The total number of aerosol particles $N_{0}$ depends on the aerosol load. Aerosol optical properties are computed by applying Mie calculations

(Mie, 1908) except for non-spherical dust particles where the T-matrix method is used (Mischenko and Davis, 1994). These calculations require knowledge of the aerosol particle size distribution and refractive index which for the the aerosol components used here are given in Table 1.

The LUTs are computed for discrete sun zenith, viewing zenith and relative azimuth angles, for each AATSR wavelength, and for a number of reference AOD levels. Currently, 15 discrete values ranging from 0 to $90^{\circ}$ are used for the zenith angles and 19 discrete values between 0 and $180^{\circ}$ are used for the azimuth angles. Typically ten AOD levels ranging from 0.05 to 4.0 at $\lambda=0.500 \mu \mathrm{m}$ are used. Transmittance and reflectance for Rayleigh (gas) scattering are computed in standard atmospheric conditions. To ensure that the result of the radiation transfer computations are not influenced by refraction effects due to the earth curvature, the maximum values for the sun and viewing zenith angles has been set to $75^{\circ}$.
AMTD

$6,4039-4075,2013$

\section{AATSR aerosol retrieval uncertainty \\ P. Kolmonen et al.}

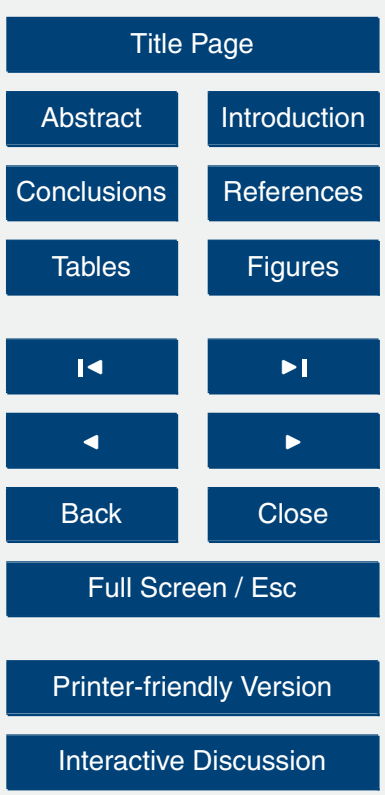


Equation (9) shows that the computational task is to find the aerosol component mixture and reference AOD level that solve the equation for all three AATSR wavelengths simultaneously. Due to measurement and modeling errors this task is impossible in practice. Instead, the task can be converted to a least-squares type of problem

$5 \quad \arg _{b_{\text {fine }}, b_{\text {naf }}, L} \min \sum_{i=1}^{N_{\lambda}}\left[\frac{\rho_{\mathrm{m}}^{\mathrm{n}}\left(\lambda_{i}\right)-\rho_{\mathrm{a}}^{\mathrm{n}}\left(b_{\text {fine }}, b_{\mathrm{naf}}, L, \lambda_{i}\right)}{T^{\mathrm{n}}\left(b_{\text {fine }}, b_{\text {naf }}, L, \lambda_{i}\right)}-\frac{\rho_{\mathrm{m}}^{\mathrm{f}}\left(\lambda_{i}\right)-\rho_{\mathrm{a}}^{\mathrm{f}}\left(b_{\text {fine }}, b_{\mathrm{naf}}, L, \lambda_{i}\right)}{k T^{\mathrm{f}}\left(b_{\text {fine }}, b_{\text {naf }}, L, \lambda_{i}\right)}\right]^{2}$,

where the subscript $m$ now indicates the measured TOA reflectance. The fraction of the fine mode particles is $b_{\text {fine }} \in(0,1)$, the non-absorbing component in fine particle mixture is $b_{\text {naf }}=b_{\text {naf, } \mathrm{A}} \pm 0.3$ with $b_{\text {naf }} \in(0,1)$, and the reference AOD level is $L \in(1,10)$. The mixture $b_{\text {naf,A }}$ is the AEROCOM a priori value. Note that the dust fraction is not 10 retrieved but the AEROCOM climatology value is used. The angle arguments $\left(\mu_{0}, \mu, \phi\right)$ have been omitted for brevity. The number of wavelengths $N_{\lambda}=3$.

The reference AOD level $L$ is here used instead of AOD as it is the parameter that is applied in the actual solving of Eq. (11). This parameter is used when AOD, aerosol reflectance, and transmittance are determined from the aerosol LUTs.

15 Equation (11) also shows that the modeled atmospheric reflectance and transmittance are functions of the decision arguments $b_{\text {fine }}, b_{\text {naf }}$ for aerosol component mixtures and $L$ for the reference AOD level. The task is now to find the decision arguments $\left(b_{\text {fine }}, b_{\text {naf }}, L\right)$ that minimize the least-squares sum. The modified linear mixing method introduced in Eq. (3) is applied with all mixtures for the computation of reflectance.

The minimization problem Eq. (11) can be optimized by applying mathematical optimization methods. Here the chosen method is Levenberg-Marquardt (see for example Gill et al., 1999). It is a trust-region type method which is well-suited for least-squares problems, and is meant for unconstrained optimization. The latter feature causes additional considerations as the decision arguments are all box-constrained. This is handled in the evaluation of the least-squares sum where strict barrier functions are used to constrain the solution (Gill et al., 1999).

\section{AMTD}

$6,4039-4075,2013$

\section{AATSR aerosol retrieval uncertainty \\ P. Kolmonen et al.}

\section{Title Page}

Abstract Introduction

Conclusions

References

Tables Figures

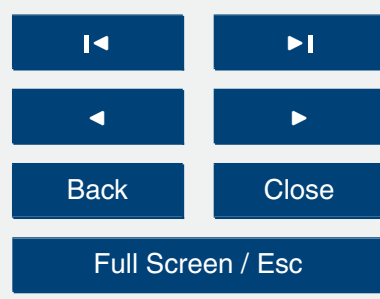

Printer-friendly Version

Interactive Discussion 
Another feature of the Levenberg-Marquardt method is that it is a local optimizer. It will converge efficiently to the nearest local minimum. To increase the probability of finding the globally best solution an initial search is done in a limited discrete set of decision parameters: ten mixtures $b_{\text {fine }}, b_{\text {naf }}$, and ten AOD levels $L$. The results of the 5 search are then used as the initial guess for the Levenberg-Marquardt method.

When all decision parameters have been set during the retrieval the resulting AOD $\tau$ can be computed from the LUTs:

$$
\begin{aligned}
\tau(\lambda)= & b_{\text {fine }}\left[b_{\text {naf }} \tau_{\text {naf }}(\lambda, L)+\left(1-b_{\text {naf }}\right) \tau_{\text {af }}(\lambda, L)\right] \\
& +\left(1-b_{\text {fine }}\right)\left[b_{\text {dust }} \tau_{\text {dust }}(\lambda, L)+\left(1-b_{\text {dust }}\right) \tau_{\text {ss }}(\lambda, L)\right],
\end{aligned}
$$

where the abbreviations are: naf - non-absorbing fine component, af - aborbing fine component, and ss - sea salt coarse component. Dust fraction $b_{\text {dust }}$ is the above mentioned AEROCOM a piori value.

\subsection{Uncertainty estimation for ADV}

15 The effect of AATSR measurement error on the retrieved AOD is described. First the uncertainty for the retrieved aerosol model decision parameters, which include the fine mode fraction $b_{\text {fine }}$, the absorbing/non-absorbing fine particle mixture $b_{\text {naf }}$, and the AOD level $L$, is determined. Then these uncertainties are used to determine the final uncertainty in the retrieved AOD.

20 The other possible sources for errors arise from modeling. These include uncertainty in the aerosol model selection (fine mode fraction, absorbing/non-absorbing fine particle mixture, dust fraction), LUT interpolation errors, and radiative transfer computation errors.

The formal treatment is based on the general equation formalism by Tarantola (1987) 25

$\mathbf{x}=\left\{b_{\text {fine }}, b_{\text {naf }}, L, \mathbf{r}\right\}$,

\section{AMTD}

$6,4039-4075,2013$

AATSR aerosol retrieval uncertainty

P. Kolmonen et al.

\section{Title Page}

Abstract Introduction

Full Screen / Esc

Printer-friendly Version

Interactive Discussion 
and the problem equations by

$f_{i}(\mathbf{x})=\frac{\rho_{\mathrm{m}}^{\mathrm{n}}\left(\lambda_{i}\right)-\rho_{\mathrm{a}}^{\mathrm{n}}\left(b_{\text {fine }}, b_{\text {naf }}, L, \lambda_{i}\right)}{T^{\mathrm{n}}\left(b_{\text {fine }}, b_{\text {naf }}, L, \lambda_{i}\right)}-\frac{\rho_{\mathrm{m}}^{\mathrm{f}}\left(\lambda_{i}\right)-\rho_{\mathrm{a}}^{\mathrm{f}}\left(b_{\text {fine }}, b_{\text {naf }}, L, \lambda_{j}\right)}{k T^{\mathrm{f}}\left(b_{\text {fine }}, b_{\text {naf }}, L, \lambda_{i}\right)}$,

where $\mathbf{r}=\left\{\rho_{\mathrm{m}}^{\mathrm{n}}\left(\lambda_{i}\right), \rho_{\mathrm{m}}^{\mathrm{f}}\left(\lambda_{i}\right)\right\} \forall i \in(1,3)$ is the measured nadir and forward reflectance. Index $i$ refers to the wavelengths; $i=\{1,2,3\}$. This kind of formulation of the problem 5 enables the determination of uncertainty in the decision parameters based on the measurement error. The formulation could take into account the effect of a priori information for $b_{\text {fine }}, b_{\text {naf }}$ and $L$ but this is neglected as the only error is assumed to come from the measurement.

Equation (14) can be solved in a least-squares sense using a quasi-Newton method.

10 The maximum likelihood point can be found using iteration

$\mathbf{x}_{n+1}=\mathbf{C}_{X} \mathbf{F}_{n}^{t}\left(\mathbf{C}_{T}+\mathbf{F}_{n} \mathbf{C}_{X} \mathbf{F}_{n}^{t}\right)^{-1} \mathbf{f}\left(\mathbf{x}_{n}\right)$,

where

$\mathbf{F}_{n}=\left(\frac{\partial \mathbf{f}}{\partial \mathbf{x}}\right)_{\mathbf{x}_{n}}$

The a posteriori covariance is

$\mathbf{C}_{X^{\prime}}=\left(\mathbf{F}_{\infty}^{t} \mathbf{C}_{T}^{-1} \mathbf{F}_{\infty}+\mathbf{C}_{X}^{-1}\right)^{-1}$

where $\mathbf{x}_{\infty}$ is the solution of the minimized Eq. (14). Note that even though the ADV solution is not computed using the iteration scheme above it is still possible to determine the a posteriori covariance.

The Jacobian matrix $\mathbf{F}$ is of the form

$20 \quad \mathbf{F}=\left(\begin{array}{lll}\frac{\partial f_{1}}{\partial b_{1}} & \frac{\partial f_{1}}{\partial b_{2}} & \frac{\partial f_{1}}{\partial L} \\ \frac{\partial f_{2}}{\partial b_{1}} & \frac{\partial f_{2}}{\partial b_{2}} & \frac{\partial f_{2}}{\partial L} \\ \frac{\partial f_{3}}{\partial b_{1}} & \frac{\partial f_{3}}{\partial b_{2}} & \frac{\partial f_{3}}{\partial L}\end{array}\right)$

\section{AMTD}

$6,4039-4075,2013$

AATSR aerosol retrieval uncertainty

P. Kolmonen et al.

\section{Title Page}

Abstract

Introduction

Conclusions

References

Tables

Figures

14

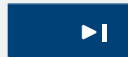

4

Back

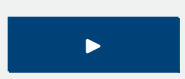

Close

Full Screen / Esc

Printer-friendly Version

Interactive Discussion 
All the partial derivates are computed numerically as the evaluation of these values requires interpolation from the aerosol LUTs and analytical differentiation is not possible.

The covariance $\mathbf{C}_{T}$ includes only measurement errors. For AATSR this error is taken to be $5 \%$ of the measured signal for the whole spectrum (Thomas et al., 2009). The 5 principal difficulty is that in Eq. (14) there are two measured values $\rho_{\mathrm{m}}^{n}\left(\lambda_{i}\right)$ and $\rho_{\mathrm{m}}^{f}\left(\lambda_{i}\right)$. The formulation in Eq. (17) takes into account the uncertainty of only one value in the covariance matrix. However, because the nadir and forward relative measurement errors are equal, the larger of the computed absolute measurement errors is used. It would be useful to study individually the effect of the nadir and forward measurement considered to be Gaussian in nature, modelling errors could be simply added to the measurement errors (Tarantola, 1987). Another simplification here is that measurement errors do not correlate. Thus, $\mathbf{C}_{T}$ is diagonal. This assumption does not hold for the a posteriori covariance $\mathbf{C}_{X^{\prime}}$. The uncertainty in the aerosol model parameters will 15 be correlated and these correlations include potentially interesting knowledge of the retrieval.

The a priori covariance matrix for the aerosol model defining parameters $\mathbf{C}_{X}$ is neglected at the moment because the uncertainty contribution of the measurement error to these very parameters is the motivation of this exercise.

$A O D$ is determined for each of the three wavelengths simultaneously, using the aerosol model defined by the three optimized decision parameters: $b_{\text {fine }}, b_{\text {naf }}$ and $L$. First, for all four aerosol components that are used the corresponding AOD is interpolated from their LUTs by using the AOD level parameter $L$. Then, simultaneously, the fine aerosol components are mixed based on the non-absorbing and absorbing AOD 25 using $b_{\text {naf }}$, and the coarse aerosol component is obtained from mixing the sea salt and dust $A O D$ using the dust fraction. The final AOD is then obtained from the fine and coarse AOD using $b_{\text {fine }}$; see Eq. (12). This is achieved as follows.

\section{AMTD}

6, 4039-4075, 2013

\section{AATSR aerosol retrieval uncertainty \\ P. Kolmonen et al.}

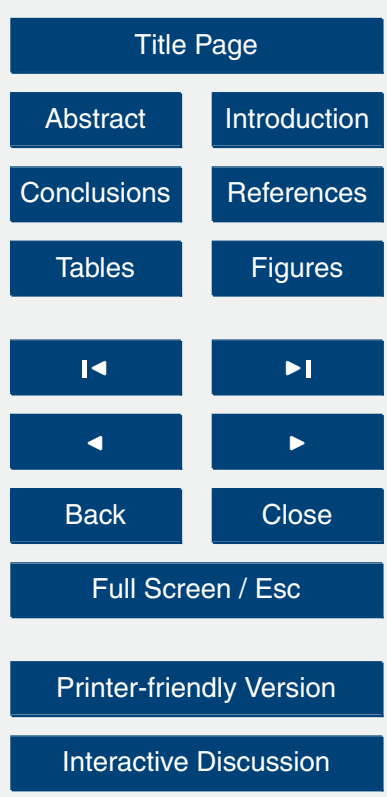


Denote the AOD interpolation/mixing operator by $p$. Then for wavelength $i$ the AOD is

$$
\tau_{i}=p_{i}\left(b_{\text {fine }}, b_{\text {naf }}, L\right) .
$$

The covariance of AOD is then (Meyer, 1975)

${ }_{5} \quad \mathbf{C}_{\mathrm{AOD}}=\mathbf{P C}_{X^{\prime}} \mathbf{P}^{t}$,

where $\mathbf{P}$ is the Jacobian of the interpolation/mixing operator:

$\mathbf{P}=\left(\begin{array}{lll}\frac{\partial p_{1}}{\partial b_{1}} & \frac{\partial p_{1}}{\partial b_{2}} & \frac{\partial p_{1}}{\partial L} \\ \frac{\partial p_{2}}{\partial b_{1}} & \frac{\partial p_{2}}{\partial b_{2}} & \frac{\partial p_{2}}{\partial L} \\ \frac{\partial p_{3}}{\partial b_{1}} & \frac{\partial p_{3}}{\partial b_{2}} & \frac{\partial p_{3}}{\partial L}\end{array}\right)$.

The uncertainty qestimate for $A O D$ can be finally found in the diagonal of $\mathbf{C}_{A O D}$.

The uncertainty of the dust fraction, which is not a retrieved parameter, could be added to $\mathbf{C}_{X^{\prime}}$ if this uncertainty was assumed to be Gaussian.

\section{ASV algorithm for over ocean retrieval}

The basic principle of the ASV algorithm is to minimize the discrepancy between the TOA measured and modelled reflectance at wavelengths of $0.555,0.659,0865$ and

$151.61 \mu \mathrm{m}$. The modelled reflectance is described below. The aerosol modelling follows the description given for the ADV algorithm. The aerosol model is based on the three mixtures that are introduced with Eq. (11).
AMTD

6, 4039-4075, 2013

AATSR aerosol retrieval uncertainty

P. Kolmonen et al.

Title Page

Abstract

Introduction

Conclusions

References

Tables

Figures

14

$\Delta$

4

Back

Close

Full Screen / Esc

Printer-friendly Version

Interactive Discussion 


\subsection{The modelled TOA reflectance over ocean}

The TOA reflectance $\rho$ over ocean is given by (Veefkind and de Leeuw, 1998):

$$
\begin{aligned}
\rho & =\rho_{\mathrm{a}}+T \downarrow \rho_{\mathrm{s}, \operatorname{dir}} /\left(1-s \rho_{\mathrm{s}, \operatorname{dir}}\right) T \uparrow+t \downarrow \rho_{\mathrm{s}, \mathrm{dif} \downarrow} T \uparrow \\
& +T \downarrow \rho_{\mathrm{s}, \operatorname{diff}} t \uparrow+t \downarrow \rho_{\mathrm{s}, \mathrm{sso}} t \uparrow,
\end{aligned}
$$

where $\rho$ is the top-of-the atmosphere reflectance, $s$ is the atmospheric backscatter ratio, $T$ is the direct transmittance and $t$ is the diffuse transmittance upwards $(\uparrow)$ and downwards $(\downarrow)$. The terms $\rho_{\mathrm{a}}$ and $\rho_{\mathrm{s}}$ are the atmospheric and surface reflectance, respectively, and the other terms come from the ocean surface model which is described in the next section. The multiple scattering between surface and atmosphere has been included only for the direct down-direct up case as it becomes negligible when diffuse transmittance is applied. Note that geometric and wavelength dependencies in Eq. (22) are omitted for brevity. The terms in Eq. (22) from left to right describe:

- Reflectance due to scattering in the atmosphere by aerosols and molecules.

- Photons transmitted downward, reflected by the ocean surface, and transmitted up.

- Photons scattered along the downward path, reflected by the ocean surface, and transmitted up.

- Photons transmitted downward, reflected by the ocean surface, and scattered towards the satellite instrument.

- Photons scattered along the downward path, reflected by the ocean surface, and scattered towards the satellite instrument.

Each of the terms in Eq. (22) contains contributions of specular (Fresnel) reflection, oceanic white caps and subsurface scattering.

\section{AATSR aerosol retrieval uncertainty \\ P. Kolmonen et al.}

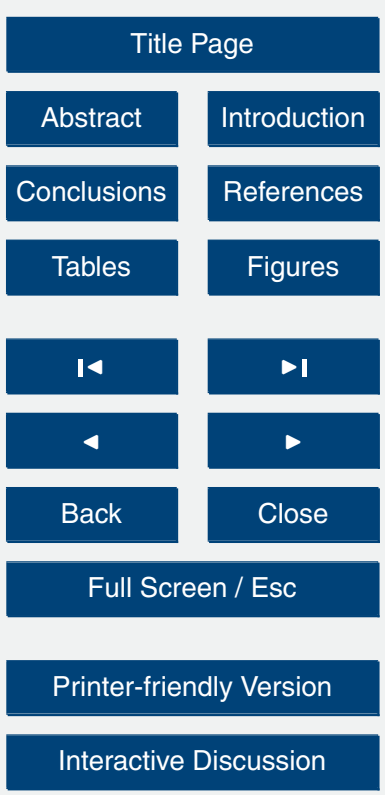




\subsection{Ocean reflectance modelling}

The ocean surface reflectance is modelled as the sum of specular (Fresnel) reflectance (Cox and Munk, 1954) and reflectance by subsurface scattering. The Fresnel part is described by the geometric situation while the subsurface scattering is a function of

5 chlorophyll concentration. The surface reflectance is a sum of four components based on atmospheric transmittance (see Eq. 22). The reflectance in these components is given by the Eqs. (23)-(26).

$\rho_{\mathrm{s}, \operatorname{dir}}\left(\mu_{0}, \mu, \phi, \lambda\right)=\rho_{\mathrm{glint}}\left(\mu_{0}, \mu, \phi, \lambda\right)+\rho_{\mathrm{chl}}(C, \lambda)$,

where $\rho_{\text {glint }}$ is the sun glint and $\rho_{\text {chl }}$ is the subsurface reflectance due to chlorophyll with 10 concentration $C$, and it is assumed here to be Lambertian (Veefkind and de Leeuw, 1998). In practice the reflectance due to sun glint is not taken into account because pixels flagged as sun glint in the AATSR L1 data are not used in the retrieved. Geometric reflectance is determined by the cosine of solar zenith angle, $\mu_{0}$, the cosine of viewing zenith angle, $\mu$, and the relative azimuth angle, $\phi$. Reflectance depends on the 15 wavelength $\lambda$. Subsurface reflectance is modelled after Morel (1988) for case I waters as

$\rho_{\mathrm{s}, \mathrm{diff} \downarrow}\left(\mu_{0}, \mu, \phi, \lambda\right)=\rho_{\text {Fresnel }}\left(\mu_{0}\right)+\rho_{\text {chl }}(C, \lambda)$

$\rho_{\mathrm{s}, \mathrm{diff} \uparrow}\left(\mu_{0}, \mu, \phi, \lambda\right)=\rho_{\text {Fresnel }}\left(\mu_{0}\right)+\rho_{\text {chl }}(C, \lambda)$

$\rho_{\mathrm{s}, \text { iso }}\left(\mu_{0}, \mu, \phi, \lambda\right)=0.066+\rho_{\mathrm{chl}}(C, \lambda)$.

20 In these equations $\rho_{\text {Fresnel }}$ is the Fresnel reflectance, and the factor 0.066 has been adapted from Ivanov (1975). The possible error caused by the approximate value is minimal because the contribution of the term described by Eq. (26) to the TOA reflectance is small. All of the above components include the contribution of the whitecap reflectance determined by the fraction of the ocean surface covered by whitecaps. The whitecap fraction $W$ is a function of wind speed $U\left(\mathrm{~ms}^{-1}\right)$ (Monahan and

\section{AMTD}

6, 4039-4075, 2013

AATSR aerosol retrieval uncertainty

P. Kolmonen et al.

\section{Title Page}

Abstract Introduction

Conclusions

References

Tables Figures

14

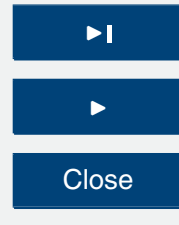

Back 
O'Muircheartaigh, 1980):

$W=3.84 \times 10^{-6} \times U^{3.41}$.

AMTD

\subsection{ASV in practice}

In the ASV retrieval the same aerosol look-up-tables are used as for the ADV retrieval.

5 There is no distinction between land and ocean retrieval with respect to aerosol components. AEROCOM a priori values and retrieval itself decide the aerosol composition for any given pixel.

As was mentioned above, the ASV method is based on minimizing the difference between the TOA measured and modelled reflectance at the four AATSR wavelengths

10 simultaneously. This leads to a minimization scheme which is considerably different from that for ADV (Eq. 11). The largest physical difference is that only one of the AATSR views is used. Currently the forward view is employed because it is less hindered by sun glint than the nadir view. The minimization in the ASV problem, following the ADV notation, is

$15 \arg _{b_{\text {fine }}, b_{\text {naf }}, L} \min \sum_{i=1}^{N_{\lambda}}\left[\rho_{\mathrm{m}}^{\mathrm{f}}\left(\lambda_{i}\right)-\rho^{\mathrm{f}}\left(b_{\text {fine }}, b_{\mathrm{naf}}, L, \lambda_{i}\right)\right]^{2}$,

with the modifications that $N_{\lambda}=4$, as the $865 \mathrm{~nm}$ wavelength is also used, and $\rho^{f}$ from Eq. (22) is now the modelled atmospheric and ocean surface reflectance. Subscript $m$ indicates the measured TOA reflectance.

\subsection{Uncertainty estimation for ASV}

20 The effect of AATSR measurement error on the retrieved AOD described for the ADV algorithm in Sect. 2.3 can straightforwardly be applied to ASV by replacing Eq. (14) with the ASV minimization from Eq. (28):

$f_{i}(\mathbf{x})=\rho_{\mathrm{m}}^{\mathrm{f}}\left(\lambda_{i}\right)-\rho^{\mathrm{f}}\left(b_{\text {fine }}, b_{\mathrm{naf}}, L, \lambda_{i}\right)$,

AATSR aerosol retrieval uncertainty

P. Kolmonen et al.

Title Page

Abstract Introduction

Conclusions

References

Tables

Figures

14

$\rightarrow 1$

4

Back

Close

Full Screen / Esc

Printer-friendly Version

Interactive Discussion 
and performing the computations as described in the ADV uncertainty characterization.

\subsection{Cloud screening}

Clouded pixels have to be excluded from retrieval as they mask the other atmospheric contributions to the measured TOA reflectance. The tests that are described here were

5 designed for the use with ATSR-2 data. For AATSR cloud flags are included in the reflectance data (AATSR Handbook, 2007). However, these flags were found to be too restrictive because a significant amount of pixels that otherwise provide good AOD values, as determined from comparison with ground-based sun photometer data, are flagged as cloud-contaminated.

10 Therefore, three separate cloud detection tests are used. These tests are based on the work of Saunders and Kriebel (1988) and Koelemeijer et al. (2001). To automate the cloud screening, AATSR orbits are divided into scenes of $512 \times 512$ pixels. Reflectance in each of the scenes is histogrammed and the histrograms are used for the automatic determination of thresholds for the cloud tests as described by Robles González (2003). The cloud tests are:

1. The gross cloud test. In the AATSR $12 \mu \mathrm{m}$ brightness temperature channel clouds appear cooler than the underlying surface during day time. If the brightness temperature for a pixel is below threshold, the pixel is flagged as cloudy.

2. Generally, clouds are brighter than the underlying surface. If the reflectance of the $0.659 \mu \mathrm{m}$ channel for a pixel is higher than threshold, the pixel is flagged as cloudy.

3. Ratio of the 0.865 and $0.659 \mu \mathrm{m}$ reflectance. If the ratio is around one for a pixel, the pixel is flagged as cloudy. The distance from unity that governs cloud flagging is determined by the automation.

25 These tests are applied for both AATSR views. If any of the tests indicates that a pixel is clouded, it will be excluded from the retrieval.

\section{AATSR aerosol retrieval uncertainty \\ P. Kolmonen et al.}

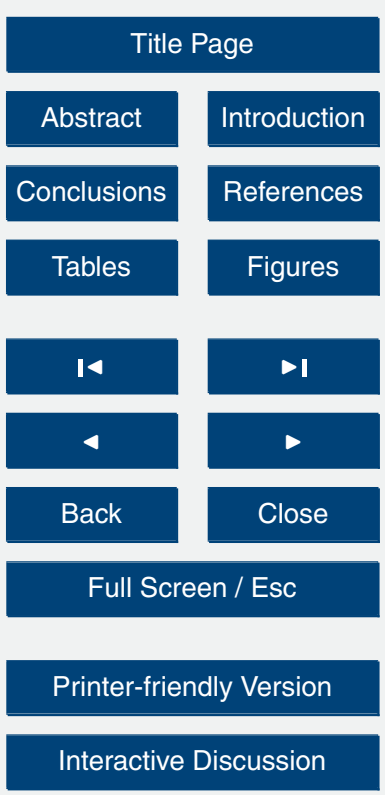




\section{The adaptation of ADV and ASV for global multi-year retrievals}

The ADV algorithm is suitable for retrieving the optical properties of aerosols over land as was demonstrated for several different areas (Veefkind et al., 2000; Robles González et al., 2000; Robles González and de Leeuw, 2008; Kokhanovsky et al.,

5 2009; Sundström et al., 2012). However, for the application to very large data sets, such as for global long-term retrieval, the time needed for retrieval computations was too long and processing of large data sets was very time consuming. The main reason was that three parameters need to be optimized during the retrieval process: the AOD reference level and the two mixtures of the aerosol components (see Eq. 11).

Where the original retrieval were made for each individual pixel $\left(1 \times 1 \mathrm{~km}^{2}\right.$ at nadir), it was decided that larger retrieval tasks should be made for enhanced default pixels (superpixel), i.e. $0.1 \times 0.1^{\circ}$. This is the level 2 (L2) result grid. The L2 results are also available in a $10 \times 10 \mathrm{~km}^{2}$ sinusoidal grid. The retrieved results are additionally given at level 3 (L3) which is averaged over a $1 \times 1^{\circ}$ grid. L3 results include all AATSR orbits, 15 usually 14 , for each day.

The added advantage of using a larger area for retrieval is that some statistical measures indicating the reliability of the retrieval can be computed using the ensemble of measured TOA reflectance values over the area.

In this section the methods for averaging the AATSR measured TOA reflectance over the superpixel are described. Also the choice of aerosol models is discussed.

\subsection{Averaging of measured reflectance for ADV and ASV}

The natural assumption when averaging TOA measured reflectance is that reflectance due to the atmosphere is sufficiently uniform over the averaged area. Here the term sufficient describes situations where no sharp spatial gradients in aerosol properties occur inside the area. Reflectance due to atmospheric gases is assumed to be uniform.

For the surface reflectance, however, this assumption can generally not be made. The complications in the averaging of the measured TOA reflectance are caused by

\section{AMTD}

6, 4039-4075, 2013

\section{AATSR aerosol retrieval uncertainty \\ P. Kolmonen et al.}

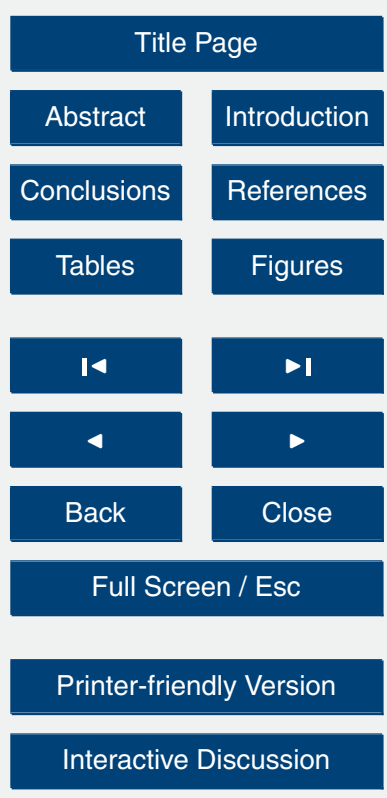


the $k$ ratio approach of the ADV. The $k$ ratio is determined by applying Eq. (7) and using the nadir and forward view surface reflectance at $1.61 \mu \mathrm{m}$. It would be unrealistic to assume that surface reflectance is constant over the larger pixel area. Reformulation of Eq. (9):

$$
{ }_{5} \frac{\left[\rho^{\mathrm{f}}\left(\mu_{0}, \mu, \phi, \lambda\right)-\rho_{\mathrm{a}}^{\mathrm{f}}\left(\mu_{0}, \mu, \phi, \lambda\right)\right] / T^{\mathrm{f}}\left(\mu_{0}, \mu, \phi, \lambda\right)}{\left[\rho^{\mathrm{n}}\left(\mu_{0}, \mu, \phi, \lambda\right)-\rho_{\mathrm{a}}^{\mathrm{n}}\left(\mu_{0}, \mu, \phi, \lambda\right)\right] / T^{\mathrm{n}}\left(\mu_{0}, \mu, \phi, \lambda\right)}=k
$$

shows that the value of $k$ strongly affects the results of a retrieval. If the $k$ ratio for the superpixel are is computed by simply averaging of all values within the pixel, the results may not be representative for any of the original pixels. As an example, consider an area where half of the larger area is covered with pixels having a high $k$ ratio and the other half having a low value. When the $k$ ratios are averaged the end result would be wrong for all of them. Furthermore, as both of the AATSR views are employed, in simple averaging of reflectance one cannot be certain that corresponding nadir/forward pixels are used when the $k$ ratio is determined. This could lead to situations where, in principle, nadir and forward view reflectance come from different pixels.
The chosen approach to average measured reflectance is to find pixels which are representative for an area, and at the same time occur in both the nadir and forward views. In ADV this is achieved by using the following method:

1. At least $50 \%$ of the pixels belonging to the superpixel area must pass the cloud screening tests. This step ensures that enough information is present for the following steps.

2. Produce a histogram of the measured reflectance at $1.61 \mu \mathrm{m}$ separately for nadir and forward reflectance. Typically seven bins are used ranging from zero to the maximum of the measured reflectance. The near-infrared channel is used here because the effect of aerosols is small. That is, the measured reflectance is considered in first approximation to have contributions from the surface only.

\section{AMTD}

$6,4039-4075,2013$

\section{AATSR aerosol retrieval uncertainty \\ P. Kolmonen et al.}

\section{Title Page}

Abstract Introduction

Conclusions

References

Tables

Figures

14

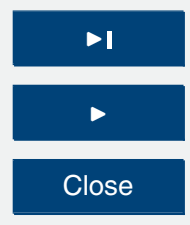

Back

Close

Full Screen / Esc

Printer-friendly Version

Interactive Discussion 
3. Choose the nadir/forward bins that have the maximum number of reflectance values.

4. Find out which pixels that are in the chosen bins are mutual to nadir and forward views.

$5 \quad 5$. If there are more that ten values left, average the chosen reflectance values and use them in the retrieval. If less than ten values are left, the surface reflectance in the area is considered to vary too much and retrieval is not executed.

The number of bins in the histogram determination is a compromise between loss of data and degeneration towards simple averaging. If too many bins were used, there would be too few pixels for averaging of the reflectance. This situation would be potentially poor in a statistical sense since only few pixels would represent the whole area. If too few bins were used, too wide a range of reflectance values would be accepted. This would allow pixels that could lead to a situation where the whole representative search of the $k$ ratio approach would become meaningless.

15 The over ocean ASV algorithm utilizes the above described reflectance averaging for the sake of uniformity. A simple average could be also used for the ASV as it can be assumed that the ocean surface reflectance is quite smooth over the $0.1 \times 0.1^{\circ}$ superpixel area.

The other test for the averaged reflectance measures the uniformity of the atmo20 spheric reflectance. The standard deviation of the reflectance at $0.555 \mu \mathrm{m}$ is used as a measure for the uniformity. The $0.555 \mu \mathrm{m}$ channel is utilized here as it is sensitive to both aerosol and cloud conditions. If the standard deviation of the TOA reflectance is too large for a superpixel, results are judged to be unreliable. Retrieval is still done but the results include the standard deviation which can then be applied by the end user to exclude unreliable areas. This test can be seen also as an additional spatial cloud screening but can also invalidate the superpixel in a case of large aerosol gradients such as in the presence of strong sources. Based on validation the threshold for too large standard deviation of the reflectance has been chosen to be 0.009 .

\section{AATSR aerosol retrieval uncertainty \\ P. Kolmonen et al.}

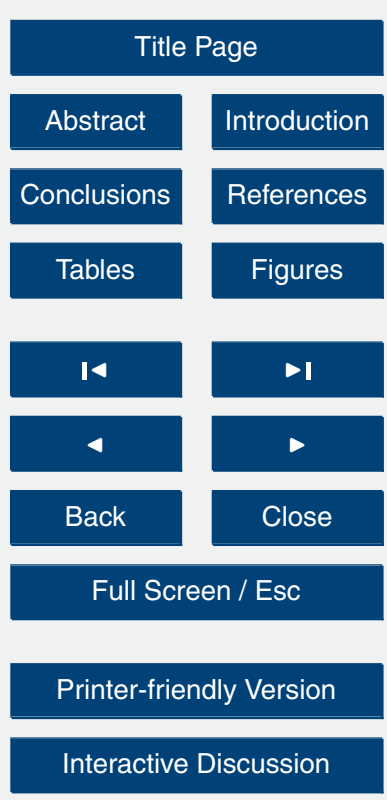




\subsection{Post processing - additional cloud screening}

For each pixel retrieved with ADV a cloud post-processing test is applied to determine and discard the pixels that might potentially include cloud edges or residual sub(super)pixel clouds. This processing also enables the removal of outliers that would 5 potentially harm the assimilation of the retrieved aerosol properties in atmospheric models.

Each pixel retrieved is analyzed together with the eight surrounding pixels in a $0.2 \times$ $0.2^{\circ}$ area. If, in addition to the tested pixel, less than 3 pixels are retrieved in the area, the tested pixel is considered to be "contaminated" and discarded. If, besides the tested pixel, at least 3 more pixels are retrieved and the AOD for the tested pixel is smaller than 0.5 , the tested pixel passes the cloud processing test. If $A O D>0.5$, an additional standard deviation test is applied. If the standard deviation of the AOD in the area is larger than 0.25 , the tested pixel is discarded.

The numbers presented above are a compromise between global coverage and ac15 ceptable validation results. However, for certain areas with high AOD (e.g. India, China),
and for case studies of natural high AOD episodes (e.g. dust storms, volcanic eruptions) different values can be used.

\subsection{The $17 \mathrm{yr}$ time series using the ATSR-2 and AATSR instruments}

Global and regional changes in aerosol conditions could potentially be investigated us20 ing the $17 \mathrm{yr}$ (1995-2012) data record of aerosol properties provided by the combined ATSR-2 (Along-Track Scanning Radiometer 2) and AATSR instruments. These two instruments have similar characteristics. However, to detect trends the reliability of the data over this long time must be ensured. Issues which need to be taken into account include the detection and removal of bias caused by systematic instrument errors, in-

The bias issue can be handled in two ways. First, both ATSR-2 and AATSR instruments have on-flight calibration and, in addition, corrections have been made for the L1

AMTD

$6,4039-4075,2013$

AATSR aerosol retrieval uncertainty

P. Kolmonen et al.

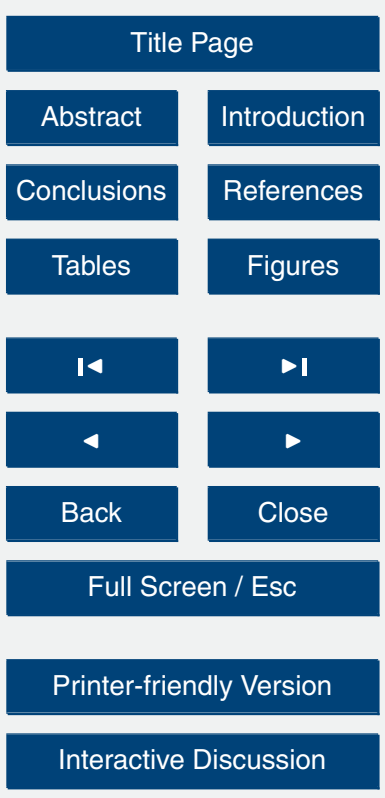


reflectance data. The L1 correction has been done by the L1 data ground processing center (RAL Space at Rutherford Appleton Laboratory, UK) by correcting the so-called drift in the measured reflectance (Smith, 2008). Second, because both the nadir and forward views of the instruments are provided by the same camera (i.e. the on-board 5 camera is tilted to produce the nadir and forward scans), it is straightforward to do the formal calculus using Eq. (1) for both views and prove that the addition of systematic error, common to both views, does not affect the final results. This indicates that when the ADV algorithm is used over land, the bias caused by instrument systematic errors could be neglected. Over ocean this does not apply as only one of the views is currently 10 used for the ASV retrieval.

The ATSR-2-AATSR continuation requires more research to verify that the combined time series produced with the ADV/ASV algorithms is reliable. Fortunately there is some overlap in the observation of the two instruments which enables to conduct the research.

\section{Results}

Results from the validation of the retrieved AOD against reference measurements in the year 2008 are presented in Sect. 5.1. Uncertainty estimates are evaluated in Sect. 5.2.

\subsection{AERONET comparison}

The most widely used validation reference for satellite-retrieved AOD is the groundbased sun photometer measurement network AERONET (Holben et al., 1998). However, the AATSR and AERONET wavelengths are not the same. Therefore, the AERONET AOD at at $0.555 \mu \mathrm{m}$ has been obtained by interpolation from the AODs at 0.440 and $0.670 \mu \mathrm{m}$. Furthermore, the AOD observations need to be collocated in time and location. This was done by considering AERONET observations within $\pm 1 / 2 \mathrm{~h}$ of the AATSR overpass. Spatially, AATSR values within a $0.25 \times 0.25^{\circ}$ area around an
AMTD

6, 4039-4075, 2013

AATSR aerosol retrieval uncertainty

P. Kolmonen et al.

\section{Title Page}

Abstract Introduction

Conclusions

References

Tables

Figures

14

$\rightarrow 1$

4

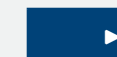

Back

Close

Full Screen / Esc

Printer-friendly Version

Interactive Discussion 
AERONET station were averaged. The validation included 198 AERONET stations. The comparison between the retrieved and reference AOD at $0.555 \mu \mathrm{m}$ for year 2008 is shown in Fig. 1.

Despite some scatter in the comparison, the overall correlation $r=0.85$ is very good. 5 Some underestimation can be seen in the linear fit (slope 0.92). This must be comfirmed with multi-year validation. The mean error is 0.02 and RMSE $=0.01$.

To assess the regional performance of the retrieval, an analysis of the discrepancy between the AATSR-retrieved and AERONET AODs was made for individual AERONET stations. Here, discrepancy is defined as AERONET AOD subtracted from 10 retrieved AATSR AOD. In the analysis at least three comparisons at a station were required to compute the average discrepancy. The discrepancies are shown in the map in Fig. 2 where they were averaged over areas of $1^{\circ} \times 1^{\circ}$. Several AERONET stations may contribute to an area, especially in Europe and North America where the station network is dense.

15 Figure 2 shows that discrepancy is low for Europe and North America while areas with bright surface and/or dust are underestimated. Coastal stations, usually based on a small island, show slight overestimation. This may require in future some adjustments in the ocean surface modeling which was described in Sect. 3.2.

\subsection{Evaluation of the uncertainty estimation}

20 The uncertainties are shown in Fig. 3, as a plot of AATSR-retrieved AOD versus AERONET AOD. For presentation clarity a small time period of two months (January and February 2008) is shown. Generally, the uncertainty seems to behave as expected. The uncertainty increases as the AOD values are higher, because the increased atmospheric reflectance due to aerosols results in higher values of the TOA reflectance, and thus the measurement error which is relative ( $5 \%$ of the measured reflectance).

Figure 4 shows a global map of the AOD at $0.555 \mu \mathrm{m}$ for autumn 2008 on a $1 \times 1^{\circ}$ (level 3) grid. These data were used to evaluate to what degree the AOD uncertainty is correlated with the AOD value. The result is shown in Fig. 5. Some correlation can

\section{AMTD}

6, 4039-4075, 2013

\section{AATSR aerosol retrieval uncertainty \\ P. Kolmonen et al.}

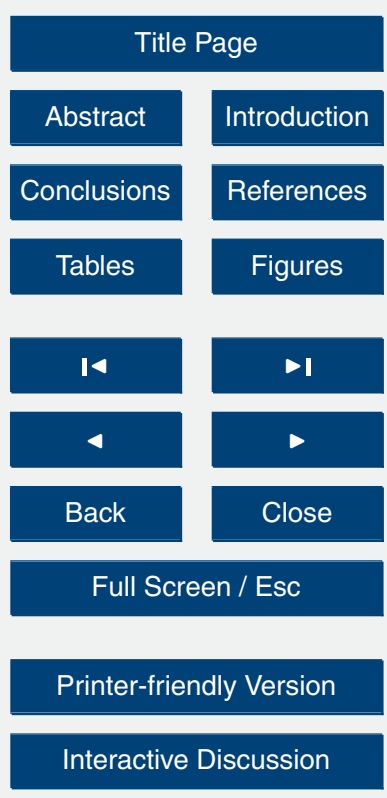


be seen but it is overshadowed by a large amount of scatter. The scatter can be explained by the fact that surface reflectance affects the determined AOD uncertainty. High surface reflectance leads to high measurement error.

The AOD uncertainty can also be compared with the discrepancy between AATSR 5 and AERONET AOD (seen in Fig. 1). This comparison is shown in Fig. 6 as a histogram. The uncertainty and discrepancy agree quite well in a statistical sense. $74 \%$ of the uncertainty - discrepancy comparison is within one standard deviation. There is a small bias indicating that on average the uncertainty has values that are larger than the discrepancy. The mean of the comparison is 0.02 with standard deviation of 0.07 .

\section{Discussion and conclusions}

The ADV/ASV algorithm for retrieving the properties of atmospheric aerosols was described. Emphasis was on the uncertainty characterization of the retrieved AOD as this is an important aspect for the use of the AOD data for assimilation in chemical transport models and for model evaluation.

15 The validation results (Figs. 1 and 2) show that the retrieved AODs compare favourably with the AERONET reference data. Some areas require further study for the enhancement of the results. Large discrepancies in these areas might be due to the basic assumptions in the algorithm which do not strictly apply (e.g. the $k$ ratio, the use of external mixtures for aerosol particles), the used aerosol modelling is not flex-

ible enough, or residual cloud contamination. The validation presented here is based on AERONET reference data over land. Data over ocean are available from, e.g., the marine aerosol network (MAN, see e.g. Smirnov et al., 2009), but for the chosen year 2008 there are insufficient data for statistical evaluation.

The uncertainty characterization currently takes into account the propagation of the 25
AMTD

$6,4039-4075,2013$

AATSR aerosol retrieval uncertainty

P. Kolmonen et al.

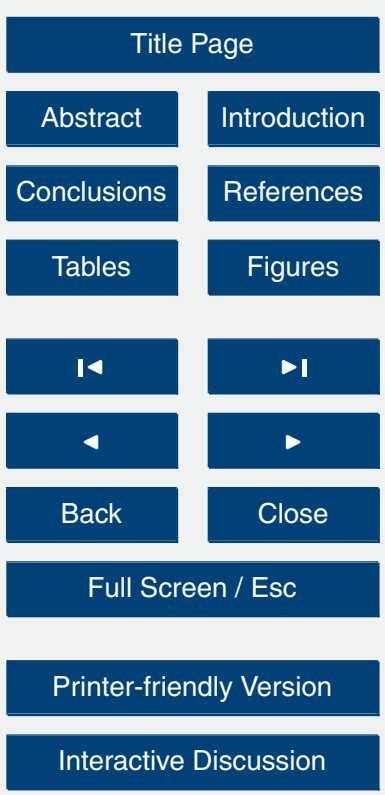


reflectance leading to low measured TOA reflectance. A more correct uncertainty over ocean could be computed by adding a sea surface modeling error. This error has been reported to be about $10 \%$ for a similar kind of ocean surface model as is used in the ASV algorithm (Sayer et al., 2009).

5 When the AOD uncertainty is compared with the discrepancies in the AERONET validation (Fig. 6) a statistical similarity between the uncertainty and the discrepancy can be seen. The two entities are not, however, directly comparable. The uncertainty is affected not only by the reflectance of aerosols but also by the reflectance of the underlying surface whereas the discrepancy can have various reasons.

10 One of the shortcomings of the current ADV algorithm is the exclusion of bright surface. It is not yet clear why the $k$ ratio assumption does not hold for bright surface areas. One possible way to overcome this issue would be to implement the surface treatment from North et al. (1999), which has been shown to behave reliably in high surface reflectance conditions.

15 The ENVISAT satellite ceased to provide data in April 2012. This does not, however, mean that the presented retrieval algorithms are now obsolete. On one hand, the processing of the whole $17 \mathrm{yr}$ ATSR-2-AATSR data will provide a time series for studies of global changes in aerosol conditions and it will act as a valuable reference for global climate model studies. On the other hand, the developed algorithms can be applied to data from the AATSR-like Sea and Land Surface Temperature Radiometer (SLSTR) instrument on the ESA/GMES Sentinel-3 mission which is planned for launch in April 2014.

The conclusion from the present study is that, although more work is still needed, results of the current ADV/ASV retrieval algorithm compare favourably with independent ground-based reference data and are suitable for characterizing local or global aerosol conditions and, in addition, can be used for data assimilation purposes.

Acknowledgements. This work was funded by the European Space Agency - Climate Change Initiative $(\mathrm{ESA} \mathrm{CCl})$ and the Monitoring Atmospheric Composition and Climate - Interim
AMTD

$6,4039-4075,2013$

\section{AATSR aerosol retrieval uncertainty \\ P. Kolmonen et al.}

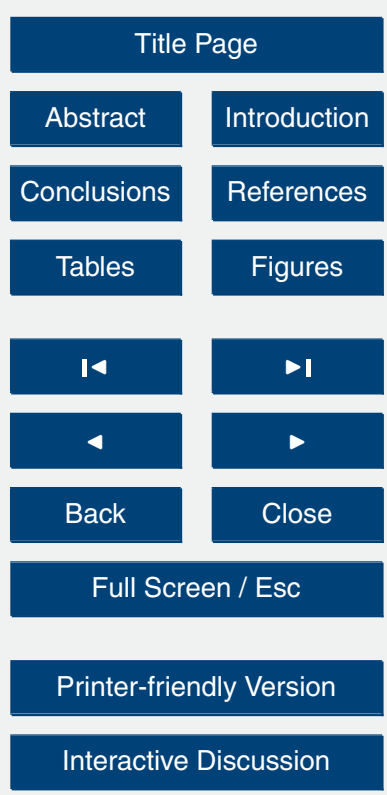


Implementation (MACC II) projects. The authors wish to acknowledge the AERONET project for providing the ground-based reference data.

\section{References}

AATSR Product Handbook: Issue 2.2, European Space Agency, available at: http://envisat.esa. int/handbooks/aatsr/, (last access: 12 December 2012), 2007. 4056

Abdou, W. A., Martonchik, J. V., Kahn, R. A., West, R. A., and Diner, D. J.: A modified linearmixing method for calculating atmospheric path radiances of aerosol mixtures, J. Geophys. Res., 102, 16883-16888, 1997. 4044

Benedetti, A., Morcrette, J.-J., Boucher, O., Dethof, A., Engelen, R. J., Fisher, M., Flentje, H., 10 Huneeus, N., Jones, L., Kaiser, J. W., Kinne, S., Mangold, A., Razinger, M., Simmnons, A. J., and Suttie, M.: Aerosol analysis and forecast in the European Centre for Medium-Range Weather Forecasts Integrated Forecast System: 2. data assimilation, J. Geophys. Res., 114, D13205, doi:10.1029/2008JD011115, 2009. 4041

Cox, C. and Munk, W.: Measurement of the roughness of the sea surface from photographs of the sun's glitter, J. Opt. Soc. Am., 44, 838-850, 1954. 4054

Curier, L., de Leeuw, G., Kolmonen, P., Sundström, A.-M., Sogacheva, L., and Bennouna, Y.: Aerosol retrieval over land using the (A)ATSR dual-view algorithm, in: Satellite Aerosol Remote Sensing over Land, edited by: Kokhanovsky, A. A. and de Leeuw, G., Springer, Berlin, 2009. 4042, 4043

de Haan, J. F., Bosma, P. B., and Hovenier, J. W.: The adding method for multiple scattering computations of polarized light, Astron. Astrophys., 183, 371-381, 1987. 4047

de Leeuw, G., Holzer-Popp, T., Bevan, S., Davies, W., Descloitres, J., Grainger, R. G., Griesfeller, J., Heckel, A., Kinne, S., Klüser, L., Kolmonen, P., Litvinov, P., Martynenko, D., North, P. J. R., Ovigneur, B., Pascal, N., Poulsen, C., Ramon, D., Schulz, M., Siddans, R., Sogacheva, L., Tanré, D., Thomas, G. E., Virtanen, T. H., von Hoyningen-Huene, W., Vountas, M., and Pinnock, S.: Evaluation of seven European aerosol optical depth retrieval algorithms for climate analysis, Remote Sens. Environ., in press, 2013.

Flowerdew, R. J. and Haigh, J. D.: An approximation to improve accuracy in the derivation of surface reflectances from multi-look satellite radiometers, Geophys. Res. Lett., 22, 16931696, 1995. 4045
AMTD

$6,4039-4075,2013$

\section{AATSR aerosol retrieval uncertainty \\ P. Kolmonen et al.}

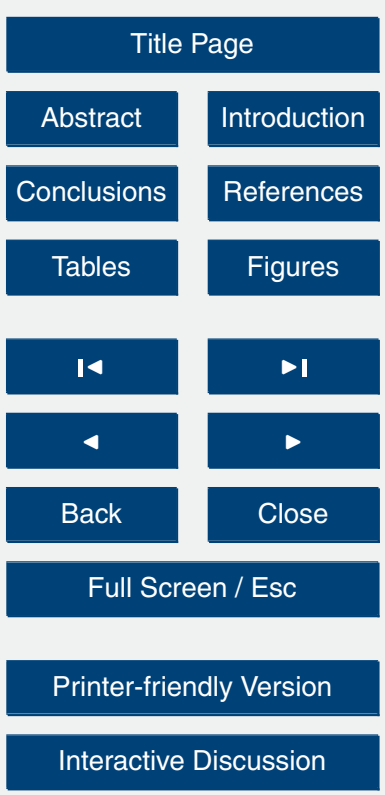


Gill, P. E., Murray, W., and Wright, M.H: Practical Optimization, Academic Press, London, the United Kingdom, 1999. 4048

Grey, W., North, P., and Los, S.: Computationally efficient method for retrieving aerosol optical depth from ATSR-2 and AATSR data, Appl. Optics, 45, 2786-2795, 2006. 4042

5 Heintzenberg, J.: Properties of the log-normal particle size distribution, Aerosol Sci. Tech., 21, 46-48, 1994. 4047

Holben, B. N., Eck, T. F., Slutsker, I., Tanré, D., Buis, J. P., Setzer, A., Vermote, E., Reagan, J. A., Kaufman, Y., Nakajima, T., Lavenu, F., Jankowiak, I., and Smirnov, A.: AERONET - a federated instrument network and data archive for aerosol characterization, Remote Sens. Environ., 66, 1-16, 1998. 4061

Holzer-Popp, T., de Leeuw, G., Martynenko, D., Klüser, L., Bevan, S., Davies, W., Ducos, F., Deuzé, J. L., Graigner, R. G., Heckel, A., von Hoyningen-Hüne, W., Kolmonen, P., Litvinov, P., North, P., Poulsen, C. A., Ramon, D., Siddans, R., Sogacheva, L., Tanre, D., Thomas, G. E., Vountas, M., Descloitres, J., Griesfeller, J., Kinne, S., Schulz, M., and Pinnock, S.: Aerosol retrieval experiments in the ESA Aerosol_cci project, Atmos. Meas. Tech. Discuss., 6, 23532411, doi:10.5194/amtd-6-2353-2013, 2013.

Huneeus, N., Chevallier, F., and Boucher, O.: Estimating aerosol emissions by assimilating observed aerosol optical depth in a global aerosol model, Atmos. Chem. Phys., 12, 45854606, doi:10.5194/acp-12-4585-2012, 2012. 4041

Hyer, E. J., Reid, J. S., and Zhang, J.: An over-land aerosol optical depth data set for data assimilation by filtering, correction, and aggregation of MODIS Collection 5 optical depth retrievals, Atmos. Meas. Tech., 4, 379-408, doi:10.5194/amt-4-379-2011, 2011. 4041

Ivanov, A. P.: Physical Properties of Hydro-optics, Nauka i Tekhnika, Minsk, 1975. 4054

Koelemeijer, R. B. A., Stammes, P., Hovenier, J. W., and de Haan, J. D.: A fast method for retrieval of cloud parameters using oxygen A-band measurements from the global ozone monitoring instrument, J. Geophys. Res., 106, 3475-3490, 2001. 4056

Kokhanovsky, A. A., Curier, R. L., Bennouna, Y., Schoemaker, R., de Leeuw, G., North, P. R. J., Grey, W. M. F., and Lee, K.-H.: The inter-comparison of AATSR dual view aerosol optical thickness retrievals with results from various algorithms and instruments, Int. J. Remote 30 Sens., 30, 4525-4537, 2009. 4057

Mie, G.: Beiträge zur Optik trüber Medien, speziell kolloidaler Metallösungen, Ann. Phys., 330, 377-445, 1908. 4047

Meyer, S. L.: Data Analysis for Scientists and Engineers, Wiley, New York, USA, 1975. 4052

\section{AMTD}

6, 4039-4075, 2013

\section{AATSR aerosol retrieval uncertainty \\ P. Kolmonen et al.}

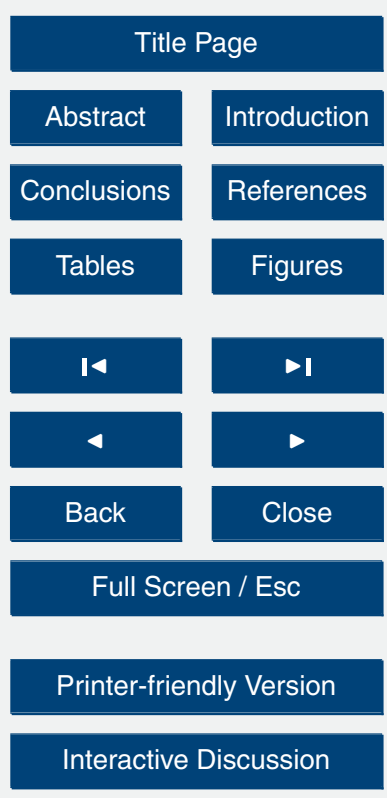


Mishchenko, M. I. and Davis, L. D.: T-matrix computations of light-scattering by large spheroidal particles, Opt. Commun., 109, 16-21, 1994. 4047

Monahan, E. C. and O'Muircheartaigh, I.: Optimal power-law description of oceanic whitecap coverage dependence on wind speed, J. Phys. Oceanogr., 10, 2094-2099, 1980. 4054

5 Morel, A.: Optical modeling of the upper ocean in relation to its biogeneous matter content (case I waters), J. Geophys. Res., 93, 10749-10768, 1988. 4054

North, P. R. J., Briggs, S. A., Plummer, S. E., and Settle, J. J.: Retrieval of land surface bidirectional reflectance and aerosol opacity from ATSR-2 multi-angle imagery, IEEE T. Geosci. Remote, 37, 526-537, 1999. 4042, 4064

10 Robles González, C.: Retrieval of Aerosol Properties Using ATSR-2 Observations and Their Interpretation, Ph. D. thesis, University of Utrecht, Utrecht, the Netherlands, 2003. 4043, 4056

Robles González, C. and de Leeuw, G.: Aerosol properties over the SAFARI-2000 area retrieved from ATSR-2, J. Geophys. Res., 113, D05206, doi:10.1029/2007JD008636, 2008. 4057

Robles González, C., Veefkind, J. P., and de Leeuw, G.: Mean aerosol optical depth over Europe in August 1997 derived from ATSR-2 data, Geophys. Res. Lett., 27, 955-959, 2000. 4046, 4057

Saunders, R. W. and Kriebel, K. T.: An improved method for detecting clear sky and cloudy radiances from AVHRR data, Int. J. Remote Sens., 9, 123-150, 1988. 4056

Sayer, A. M., Thomas, G. E., and Grainger, R. G.: A sea surface reflectance model for (A)ATSR, and application to aerosol retrievals, Atmos. Meas. Tech., 3, 813-838, doi:10.5194/amt-3813-2010, 2010. 4064

Smirnov, A., Holben, B. N., Slutsker, I., Giles, D. M., McClain, C. R., Eck, T., Sakerin, S. M., Macke, A., Croot, P., Zibordi, G., Quinn, P. K., Sciare, J., Kinne, S., Harvey, M., Smyth, T. J., Piketh, S., Zielinski, T., Proshutinsky, A., Goes, J. I., Nelson, N. B., Larouche, P., Radionov, V. F., Goloub, P., Moorthy, K. K., Matarrese, R., Robertson, E. J., and Jourdin, F.: Maritime Aerosol Network as a component of Aerosol Robotic Network, J. Geophys. Res., 114, D06204, doi:10.1029/2008JD011257, 2009. 4063

30 Smith, D. L.: Final report on multi-mission calibration study, PO-RP-RAL-AT-0599, Envisat project document, RAL Space, Oxford, the United Kingdom, 2008. 4061
AMTD

6, 4039-4075, 2013

AATSR aerosol retrieval uncertainty

P. Kolmonen et al.

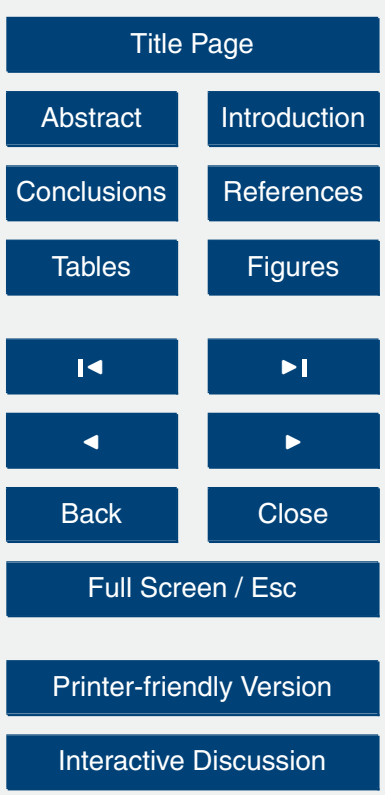


Sundström, A.-M., Kolmonen, P., Sogacheva, L., and de Leeuw, G.: Aerosol retrievals over China with the AATSR Dual-View Algorithm, Remote Sens. Environ., 116, 189-198, 2012. 4057

Tarantola, A.: Inverse Problem Theory, Elsevier, Amsterdam, the Netherlands, 1987. 4049, 4051

Thomas, G. E., Carboni, E., Sayer, A. M., Poulsen, C. A., Siddans, R., and R. G. Grainger: Oxford-RAL Aerosol and Cloud (ORAC): aerosol retrievals from satellite radiometers, in: Satellite Aerosol Remote Sensing Over Land, edited by: Kokhanovsky, A. A. and de Leeuw, G., Springer, Berlin, Germany, 193-225, 2009. 4042, 4051

10 Veefkind, J. P. and de Leeuw, G.: A new algorithm to determine the spectral aerosol optical depth from satellite radiometer measurements, J. Aerosol Sci., 29, 1237-1248, 1998. 4042, 4053

Veefkind, J. P., de Leeuw, G. D., and Durkee, P. A.: Retrieval of aerosol optical depth over land using two-angle view satellite radiometry during TARFOX, Geophys. Res. Lett., 25, 3135-

$15 \quad 3138,1999.4042,4043$

Veefkind, J. P., de Leeuw, G. D., Stammes, P., and Koelemeijer, R. B. A.: Regional distribution of aerosol over land, derived from ATSR-2 and GOME, Remote Sens. Environ., 74, 377-386, 2000. 4043, 4044, 4057

Wanner, W., Strahler, A. H., Hu, B., Lewis, P., Muller, J.-P., Li, X., Barker Schaaf, C. L., and MODIS and MISR data: theory and algorithm, J. Geophys. Res., 102, 17143-17161, 1997. 4044

\section{AMTD}

6, 4039-4075, 2013

AATSR aerosol retrieval uncertainty

P. Kolmonen et al.

\section{Title Page}

Abstract Introduction

Conclusions

References

Tables

Figures

14

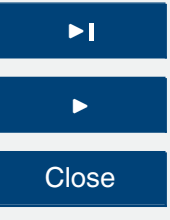

Back

4

Full Screen / Esc

Printer-friendly Version

Interactive Discussion 
AMTD

$6,4039-4075,2013$

AATSR aerosol retrieval uncertainty

P. Kolmonen et al.

Table 1. The Aerosol $\mathrm{CCl}$ aerosol components. Listed are the geometric radius $r_{\mathrm{g}}$, standard deviation $\sigma$, refractive index $n$, and the aerosol layer height (alh).

\begin{tabular}{lrccc}
\hline component & $r_{\mathrm{g}}(\mu \mathrm{m})$ & $\sigma$ & $n$ & alh $(\mathrm{km})$ \\
\hline non-absorbing fine & 0.07 & 1.700 & $1.40-0.003 \mathrm{i}$ & $0-2$ \\
absorbing fine & 0.07 & 1.700 & $1.50-0.040 \mathrm{i}$ & $0-2$ \\
sea salt & 0.788 & 1.822 & $1.40-0.000 \mathrm{i}$ & $0-1$ \\
dust & 0.788 & 1.822 & $1.56-0.002 \mathrm{i}$ & $2-4$ \\
\hline
\end{tabular}

Abstract

Introduction

Conclusions

References

Tables

Figures

14

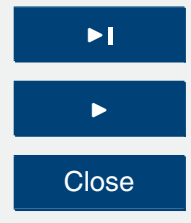

Full Screen / Esc

Printer-friendly Version

Interactive Discussion 


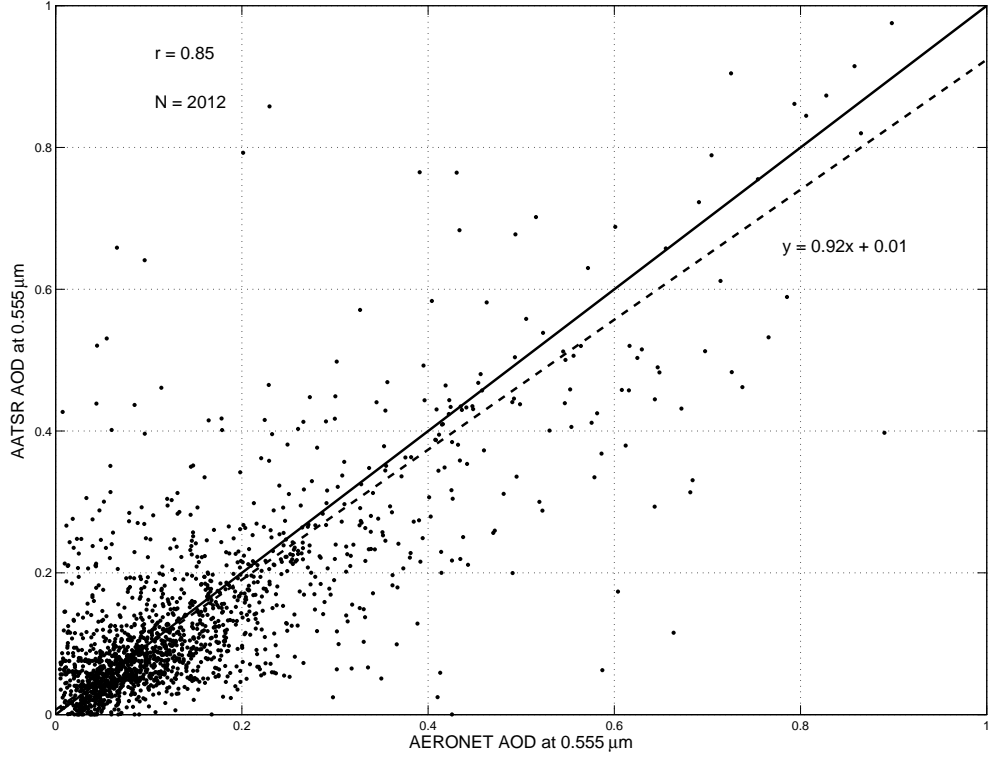

Fig. 1. Comparison of $A O D$ at $0.555 \mu \mathrm{m}$ between ADV/ASV retrieved and AERONET in the year 2008.

\section{AMTD}

$6,4039-4075,2013$

AATSR aerosol retrieval uncertainty

P. Kolmonen et al.

\begin{tabular}{|c|c|}
\hline \multicolumn{2}{|c|}{ Title Page } \\
\hline Abstract & Introduction \\
\hline Conclusions & References \\
\hline Tables & Figures \\
\hline I4 & $\bullet \mathbf{I}$ \\
\hline 4 & $\bullet$ \\
\hline Back & Close \\
\hline Full Screen / Esc \\
\hline
\end{tabular}

Printer-friendly Version

Interactive Discussion 


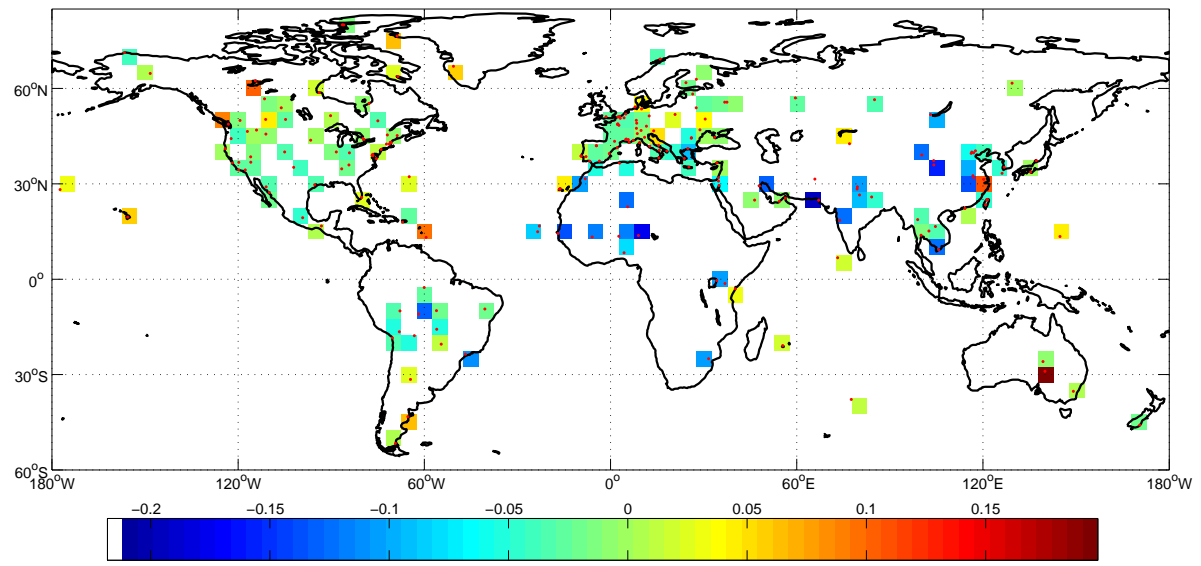

Fig. 2. Map of the AOD discrepancy (AERONET AOD subtracted from retrieved AATSR AOD) analysis by AERONET stations in the year 2008. The colored $1^{\circ} \times 1^{\circ}$ patches indicate the absolute average AOD discrepancy. The 198 AERONET stations are marked with red dots.

\section{AMTD}

$6,4039-4075,2013$

AATSR aerosol retrieval uncertainty

P. Kolmonen et al.

Title Page

Abstract

Introduction

Conclusions

References

Tables

Figures

14

$\rightarrow 1$

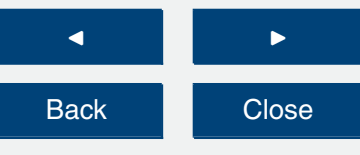

Full Screen / Esc

Printer-friendly Version

Interactive Discussion 


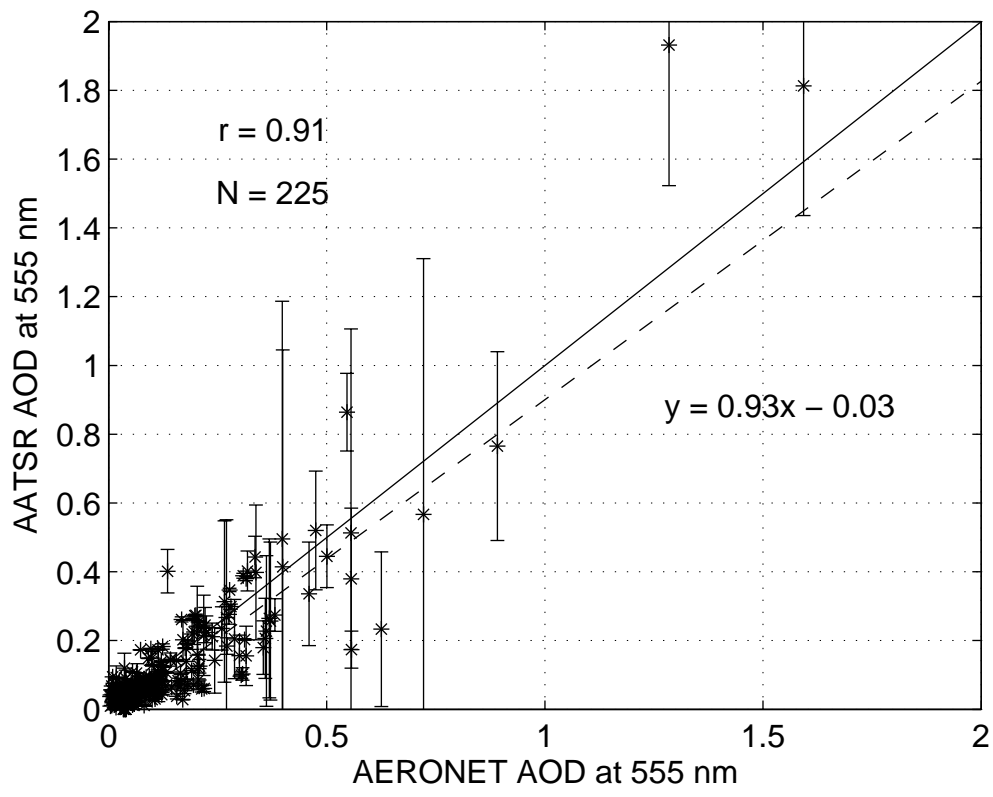

Fig. 3. Comparison of AERONET and AATSR AOD at $0.555 \mu \mathrm{m}$ for the period of JanuaryFebruary 2008. The per pixel uncertainty is also shown with error bars.
AMTD

$6,4039-4075,2013$

AATSR aerosol retrieval uncertainty

P. Kolmonen et al.

Title Page

Abstract

Introduction

Conclusions

References

Tables

Figures

14

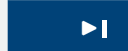

4

Back

Close

Full Screen / Esc

Printer-friendly Version

Interactive Discussion 


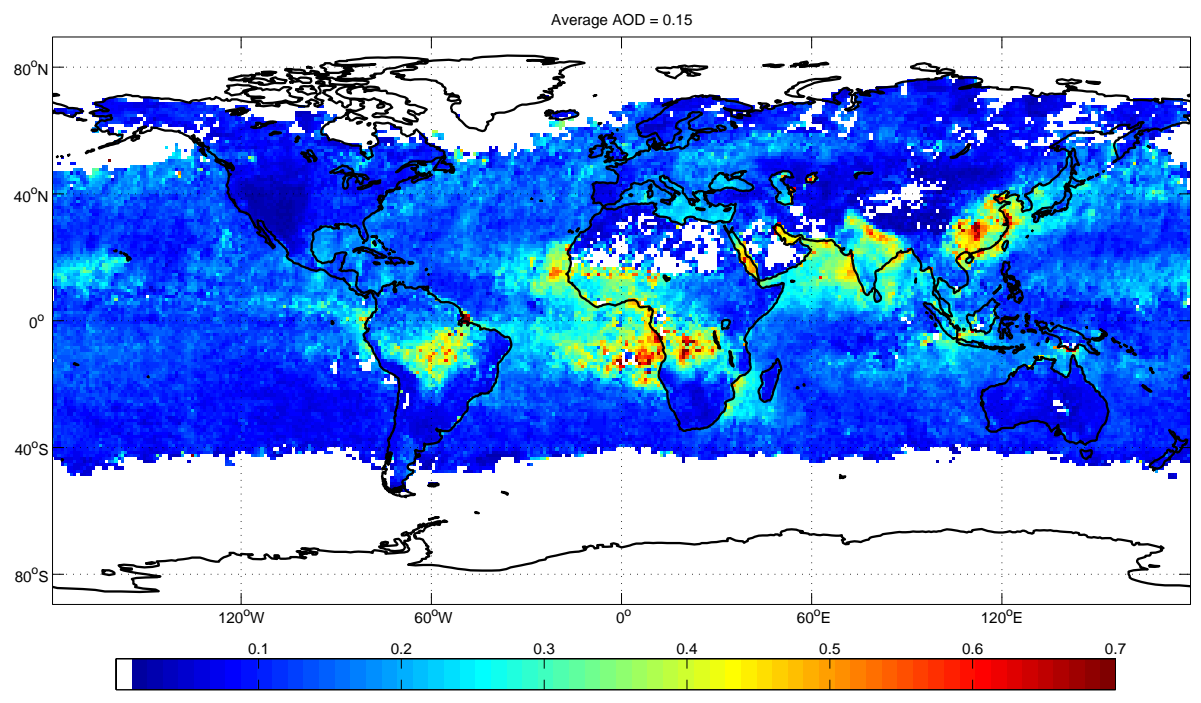

Fig. 4. Average level 3 AOD at $0.555 \mu \mathrm{m}$ for the autumn months (September, October, November) 2008.

\section{AMTD}

6, 4039-4075, 2013

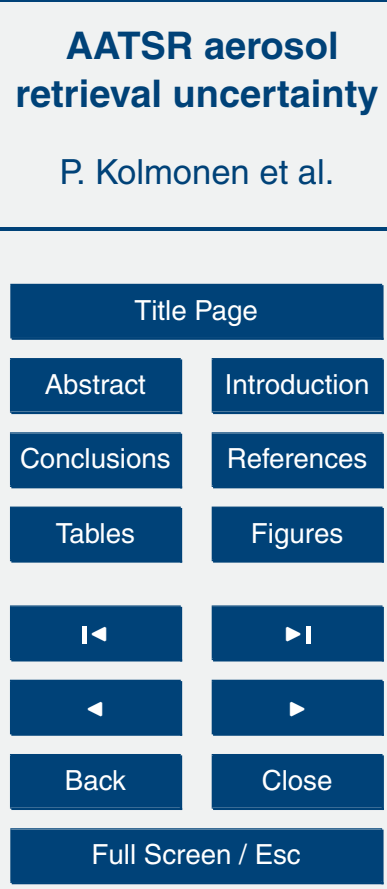

Printer-friendly Version

Interactive Discussion 


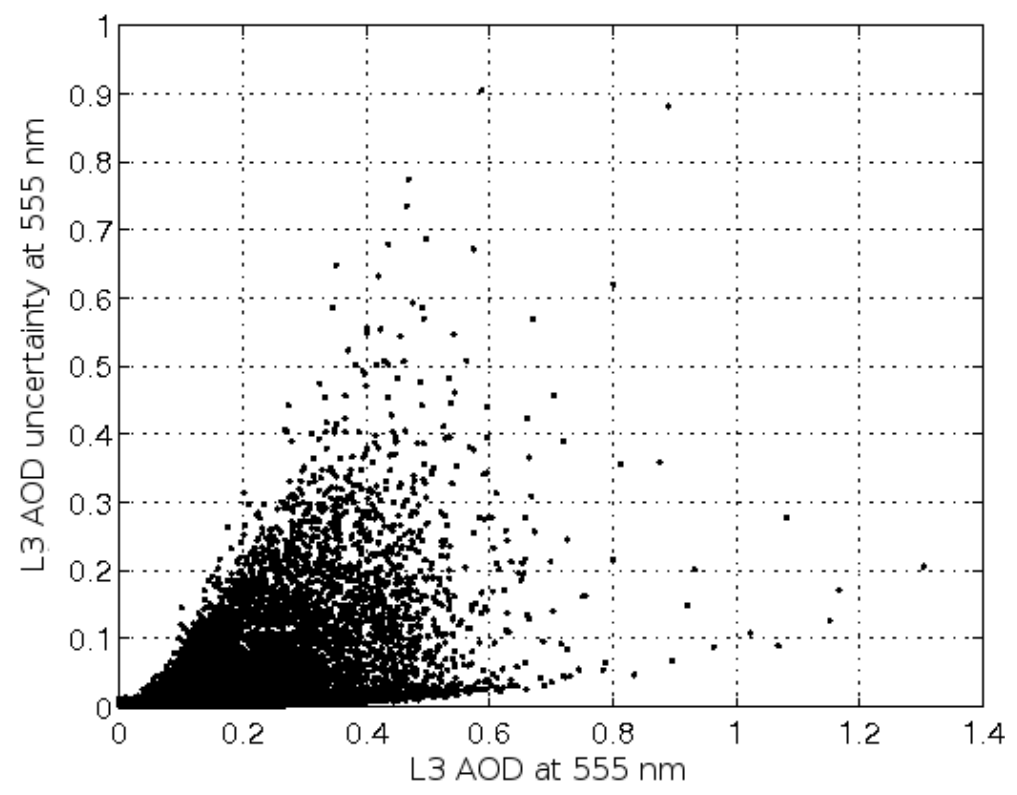

Fig. 5. The global comparison of the level 3 AOD with the level 3 AOD uncertainty.
AMTD

$6,4039-4075,2013$

AATSR aerosol retrieval uncertainty

P. Kolmonen et al.

\begin{tabular}{|c|c|}
\hline \multicolumn{2}{|c|}{ Title Page } \\
\hline Abstract & Introduction \\
\hline Conclusions & References \\
\hline Tables & Figures \\
\hline & \\
\hline I4 & $\bullet \mathbf{I}$ \\
\hline 4 & $\bullet$ \\
\hline Back & Close \\
\hline Full Screen / Esc
\end{tabular}

Printer-friendly Version

Interactive Discussion 


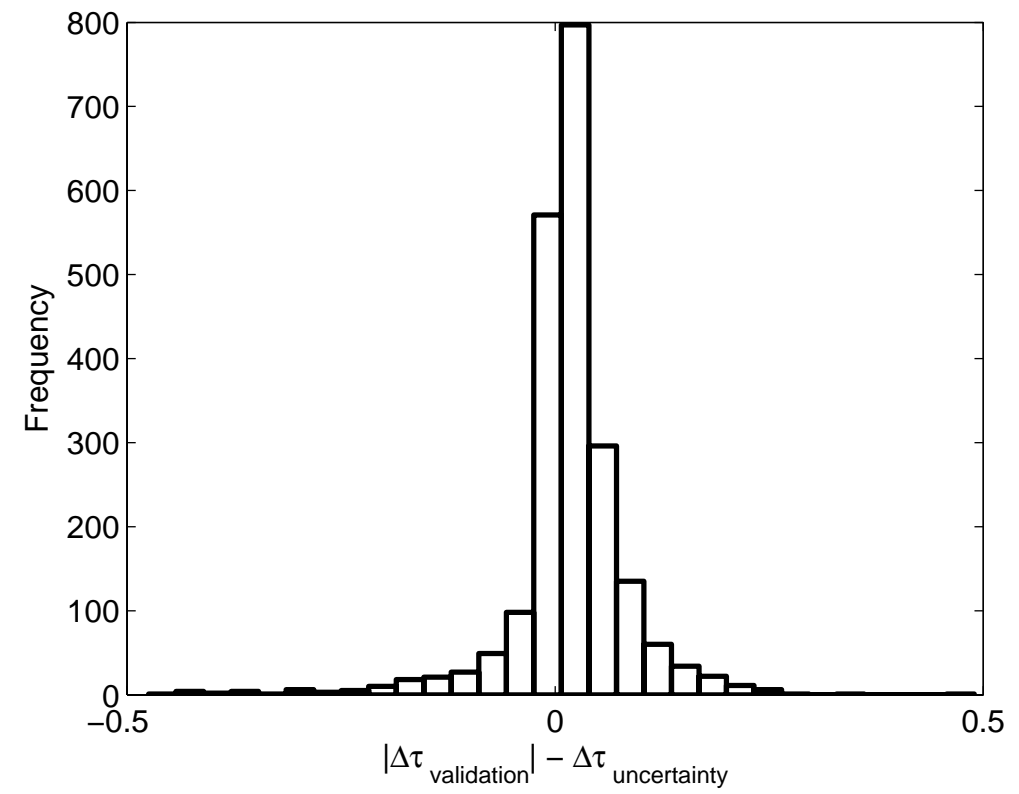

AMTD

6, 4039-4075, 2013

AATSR aerosol
retrieval uncertainty

P. Kolmonen et al.

Title Page

Abstract

Introduction

Conclusions

References

Tables

Figures

14

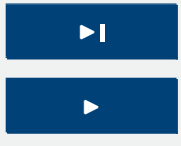

Back

Close

Full Screen / Esc

Fig. 6. Histogram of the comparison of AERONET validation discrepancy $\Delta \tau_{\text {validation }}=\tau_{\text {AATSR }}-$ $\tau_{\text {AERONET }}$ with the computed uncertainty $\Delta \tau_{\text {uncertainty }}$. The shown results were determined at $0.555 \mu \mathrm{m}$.

Printer-friendly Version

Interactive Discussion 